Check for updates

Cite this: RSC Adv., 2019, 9, 408

\title{
Recent advances on the thermal destabilization of Mg-based hydrogen storage materials
}

\author{
Jianfeng Zhang, (D) Zhinian Li, ${ }^{*}$ Yuanfang Wu, Xiumei Guo, Jianhua Ye, Baolong Yuan, \\ Shumao Wang and Lijun Jiang
}

Magnesium hydride and its compounds have a high hydrogen storage capacity and are inexpensive, and thus have been considered as one of the most promising hydrogen storage materials for on-board applications. Nevertheless, $\mathrm{Mg} / \mathrm{MgH}_{2}$ systems suffer from great drawbacks in terms of kinetics and thermodynamics for hydrogen uptake/release. Over the past decades, although significant progress has been achieved with respect to hydrogen sorption kinetics in $\mathrm{Mg} / \mathrm{MgH}_{2}$ systems, their high thermal stability remains the main drawback, which hinders their practical applications. Accordingly, herein, we present a brief summary of the synthetic routes and a comprehensive overview of the advantages and disadvantages of the promising strategies to effectively tune the thermodynamics of Mg-based materials, such as alloying, nanostructuring, metastable phase formation, changing reaction pathway, and nano Mg-based composites. Among them nanostructuring and metastable phase formation, which have the superiority of changing the thermodynamics without affecting the hydrogen capacity, have attracted increasing interest in this field. To further optimize the hydrogen storage performance, we specially emphasize novel nanostructured materials, which have the advantage of combining alloy engineering, nanostructuring and the synergistic effect to change the thermodynamics of $\mathrm{Mg} / \mathrm{MgH}_{2}$ to some extent. Furthermore, the remaining challenges and the directions of further research on $\mathrm{MgH}_{2}$, including the fundamental mechanism of the $\mathrm{Mg}-\mathrm{H}$ bond instability, advanced synthetic routes, stabilizing nanostructures, and predicting novel composite materials, are proposed.

Received 30th June 2018

Accepted 7th December 2018

DOI: $10.1039 / \mathrm{c} 8 \mathrm{ra05596c}$

rsc.li/rsc-advances state. However, currently, the storage of hydrogen gas in gas cylinders under high pressure is not safe. Similarly to pressurized hydrogen gas, liquid hydrogen possesses many difficulties related to its very low density and is not economic since a large amount of energy is consumed to cool the gas temperature to $20.2 \mathrm{~K}$. Apart from the gaseous and liquid states for hydrogen storage, solid-state hydrogen storage systems have been considered as the most reliable and safe practical solution for providing clean energy for different applications at a desired temperature with low cost and high hydrogen capacity, ${ }^{1}$ such as proton-exchange fuel cells membranes (PEM). ${ }^{2}$

In the 1960s, scientists in Holland found that the $\mathrm{SmCo}_{5}$ magnetic alloy can absorb a large amount of hydrogen. Based on this, the $\mathrm{LaNi}_{5}$-type hydrogen storage alloy was developed with a reversible hydrogen storage capacity of $1.4 \mathrm{wt} \%$ with a formation enthalpy of $-30.2 \mathrm{~kJ} \mathrm{~mol}^{-1}$ at ambient temperature. ${ }^{3}$ Around the same period, J. J. Reilly, a researcher at the Brookhaven National Laboratory in the United States, discovered the $\mathrm{Mg}_{2} \mathrm{Ni}$ hydrogen storage alloy, with a reversible hydrogen storage capacity of $3.6 \mathrm{wt} \%{ }^{4}$ In metal hydrides, the hydrogen atoms are chemically bonded with metallic elements such as intermetallic hydrides, complex hydrides, and elemental hydrides, where around 36 metallic elements can interrelate with hydrogen atoms. These metal hydrides, such as $\mathrm{LaNi}_{5}$, TiFe, and V-based solid solution, have suitable hydrogen sorption
General Research Institute for Nonferrous Metals, 2 Xinjiekou Wai Street, Beijing 100088, China. E-mail: lzngrinm@163.com; Fax: +86-10-60662619; Tel: +86-1060662633 
thermodynamics and fast kinetics, which mean that hydrogen sorption can take place at a fast rate and suitable temperatures and hydrogen pressure conditions. Unfortunately, they all have a very low gravimetric hydrogen storage density (Fig. 1) ${ }^{5}$ and are unsuitable for practical application as energy sources, particularly as on-board automotive hydrogen storage systems according to the US-Department of Energy (DOE) (Table 1). ${ }^{6}$

From Fig. 1, Mg-based hydrides can be considered as an efficient on-board hydrogen storage candidate especially for vehicular application due to their high hydrogen content of $7.6 \mathrm{wt} \%$ and volumetric density of about twice that of liquid hydrogen (consistent with the goals of the DOE). http:// www.youdao.com/w/eng/destabilized/javascript:void(0); The use of $\mathrm{Mg}$ for hydrogen storage purposes also has other potential advantages. $\mathrm{Mg}$ is the 8th most abundant element in the Earth's crust (2.3\%) and the 3rd most abundant element dissolved in sea water. Thus, Mg-based storage materials have the potential of low cost and are considered to be the most promising hydrogen storage materials for light-duty vehicles. However, a number of issues need to be solved before their practical application, such as high desorption temperature, kinetic limitations of $\mathrm{Mg} / \mathrm{MgH}_{2}$, and easy oxidation in oxygen and air. In the past few decades, significant progress has been made in improving the hydrogenation/dehydrogenation kinetics of Mg-based materials by adding a catalyst, multiphase composite, nanocrystalline and other measures. However, the tuning of their thermodynamic properties is still a great challenge. Herein, we present a summary on the recent advances and developments of $\mathrm{Mg}$ and $\mathrm{Mg}$-based materials.

\section{Magnesium hydride as hydrogen storage medium}

The crystal structure of pure magnesium is close-packed hexagonal and it can react with hydrogen at the temperature

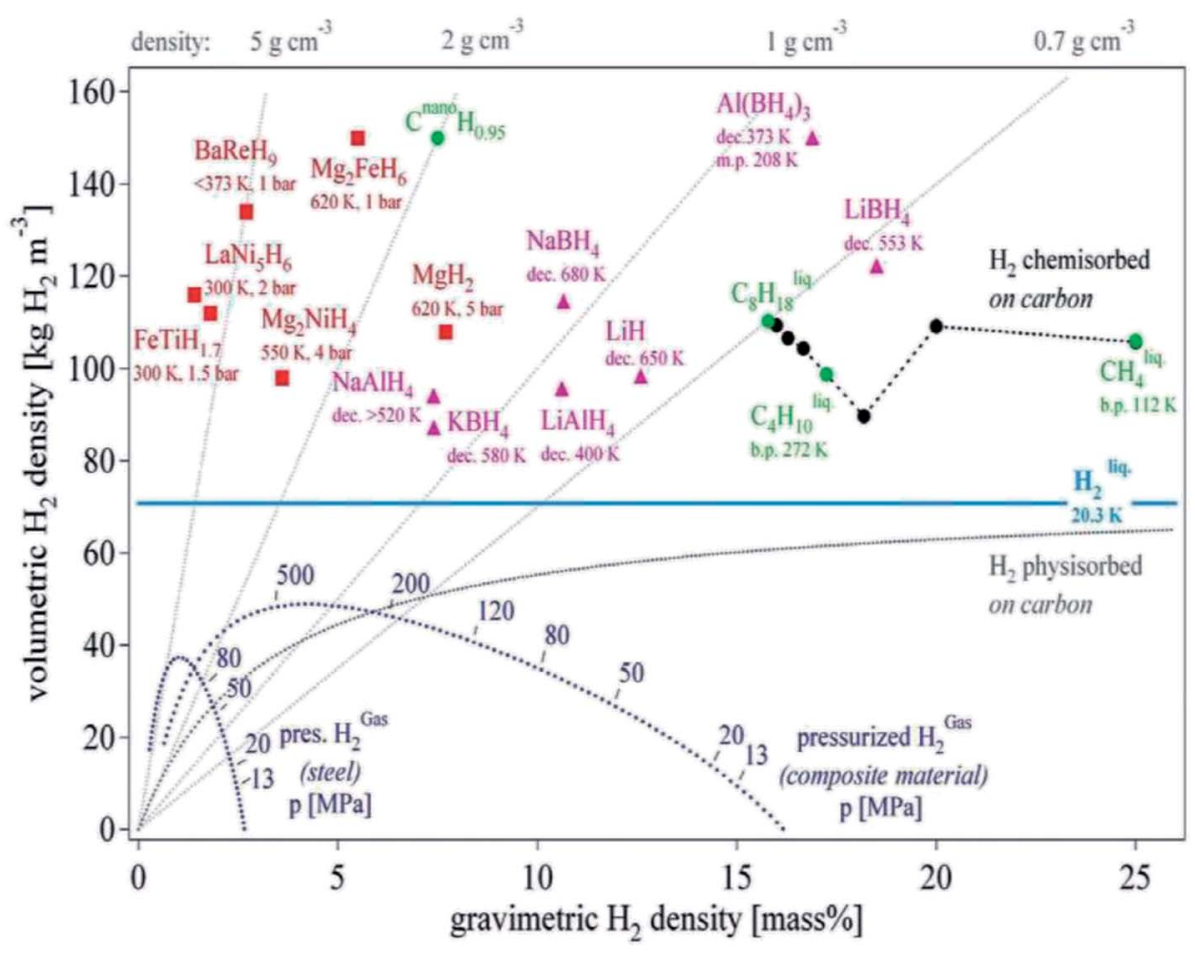

Fig. 1 Gravimetric and volumetric hydrogen density of various hydrogen storage materials. ${ }^{5}$

Table 1 Main technical targets for onboard hydrogen storage systems for light-duty fuel cell vehicles by the US DOE ${ }^{6}$

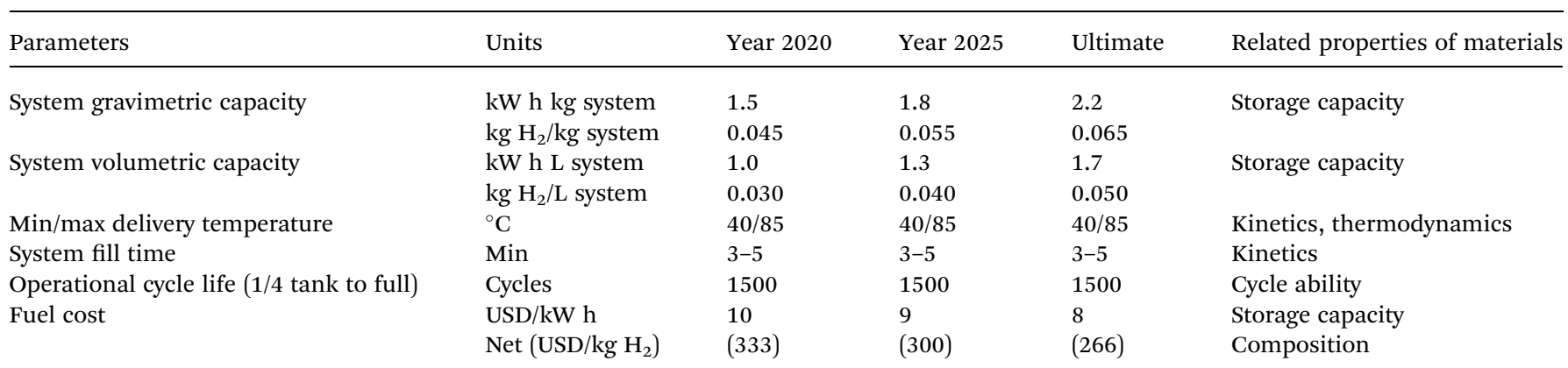


Table 2 Crystal structure data for $\mathrm{Mg}, \gamma-\mathrm{MgH}_{2}$ and $\beta-\mathrm{MgH}_{2}$ (ref. 11)

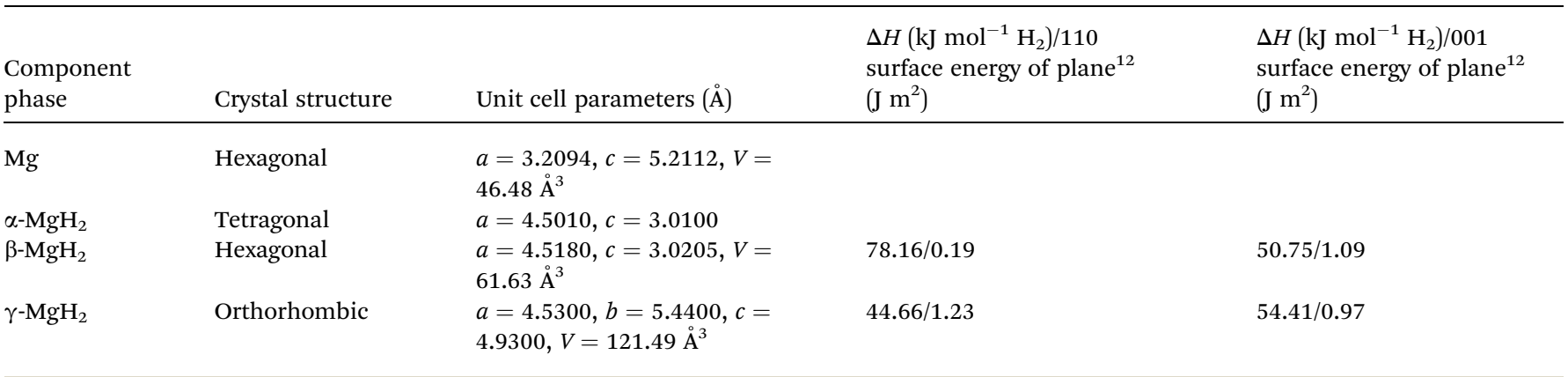

of 573-673 K and 2.4-40 bar hydrogen pressure, which involves a number of different steps, such as physisorption, dissociation, chemisorption, diffusion of hydrogen into its subsurface sites and bulk lattice sites and finally the nucleation and growth of the hydride phase. Upon the application of hydrogen pressure to $\mathrm{Mg}$, the hydrogen atoms initially occupy the tetrahedral interstitial sites within its lattice, forming a tetragonal $\alpha$-phase with a hydrogen concentration of up to $0.4 \mathrm{wt} \% .^{7}$ At higher pressures, the nucleation of the $\beta$-phase is energetically favorable and the $\alpha$-phase is converted into hexagonal structure $\beta$ $\mathrm{MgH}_{2}$. During this process, the hexagonal close-packed (hcp) lattice of $\mathrm{Mg}$ expands by approximately $30 \%$ (Table 2), and this phase further transitions to the metastable $\gamma-\mathrm{MgH}_{2}$ phase under higher compressive stress (70-80 bar)..$^{8-10}$ Recently, researchers discovered that the coexistence of different types $\mathrm{MgH}_{2}$ can produce a catalytic effect during hydrogen release/ uptake, for example, $\gamma-\mathrm{MgH}_{2}$ will make $\beta-\mathrm{MgH}_{2}$ destabilize to release hydrogen at low temperature. Unfortunately, $\gamma-\mathrm{MgH}_{2}$ will irreversibly revert to $\beta-\mathrm{MgH}_{2}$ upon the first hydrogen cycle at $573 \mathrm{~K}^{\mathbf{1 0}^{\mathbf{0}}}$

Magnesium hydride differs to other metal hydrides in its $\mathrm{M}-\mathrm{H}$ bonds and crystal structure, which is similar to ionic hydrides of alkali and alkaline earth metals. Vajeeston et al. revealed that all polymorphs of $\mathrm{MgH}_{2}$ have a dominant ionic character with $\mathrm{Mg}$ and $\mathrm{H}$ in nearly $2^{+}$and $1^{-}$states, respectively, by means of charge-density, charge-transfer, electronlocalization function and Mulliken population analyses. ${ }^{\mathbf{1 1}}$ The strong chemical bonds formed between hydrogen and metals during chemisorption explain the high storage capacity of $\mathrm{Mg}$ and its stability at room temperature. Thereby, the reaction of hydrogen with $\mathrm{Mg}$ is exothermic with an enthalpy of reaction of $-74.5 \mathrm{~kJ}\left(\mathrm{~mol}^{-1} \mathrm{H}_{2}\right)$ and an entropy variation of $-135 \mathrm{~J}\left(\mathrm{~K}^{-1}\right.$ $\mathrm{mol}^{-1} \mathrm{H}_{2}$ ), which is much larger than the practical requirements for metal hydrides of 20-40 $\mathrm{kJ} \mathrm{mol}^{-1}$ and results in a higher desorption temperature. ${ }^{13}$ Fig. 2 shows the variation in the plateau pressure as a function of temperature for $\mathrm{MgH}_{2}$. Accordingly, it can be concluded that magnesium cannot absorb hydrogen below a pressure of 10 bar if the temperature is higher than about $640 \mathrm{~K}$. Similarly, magnesium hydride has to be heated to at least $550 \mathrm{~K}$ to desorb hydrogen under 1 bar of pressure. Thus, the challenge is to reduce the operation temperature while retaining as much as possible its high hydrogen storage capacity. ${ }^{\mathbf{1 4}}$

\section{Preparation of $\mathrm{MgH}_{2}$}

The reaction of $\mathrm{Mg}$ with hydrogen yields a stable hydride as follows (1):

$$
\mathrm{Mg}+\mathrm{H}_{2} \leftrightarrow \mathrm{MgH}_{2}
$$

Thus far, many techniques have been developed to synthesize $\mathrm{MgH}_{2}$ for hydrogen storage, such as mechanical milling, ${ }^{15}$ thin film technology, ${ }^{\mathbf{1 6}}$ hydrogen plasma metal reaction, ${ }^{\mathbf{1 7}}$ hydriding chemical vapor deposition, ${ }^{18}$ melt spinning, ${ }^{19}$ severe plastic deformation, ${ }^{20}$ chemical reduction, ${ }^{21}$ and electrochemical deposition. ${ }^{22}$ One of the most commonly used techniques is reactive mechanical milling (RMM), which has been widely used to tune metal microstructures to modify their hydrogenation properties. ${ }^{23}$ Its advantages as an efficient tool for the synthesis of hydrogen storage materials include the ease of hydrogenation of $\mathrm{Mg}$-based alloys at low temperature, the generation of fresh and highly reactive surfaces, the ease of formation of multi-phase nanocomposites and creation of more defects and micro-strains in the crystal lattice due to mechanical action. ${ }^{24}$ As shown in Fig. 3, the desorption plateau of the milled sample is much higher and the hysteresis much smaller,

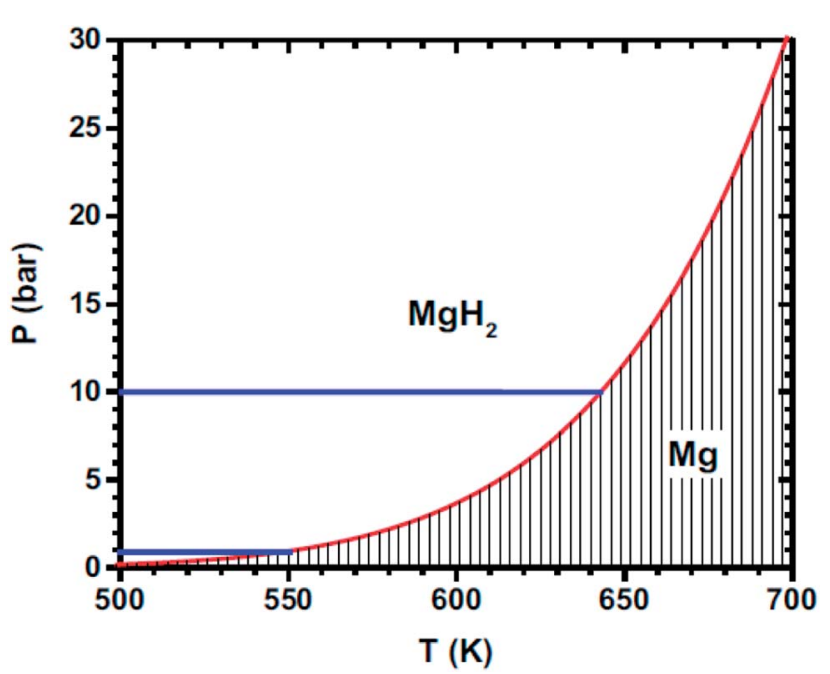

Fig. 2 Temperature dependence of the dissociation pressure of $\mathrm{MgH}_{2} \cdot{ }^{14}$ 


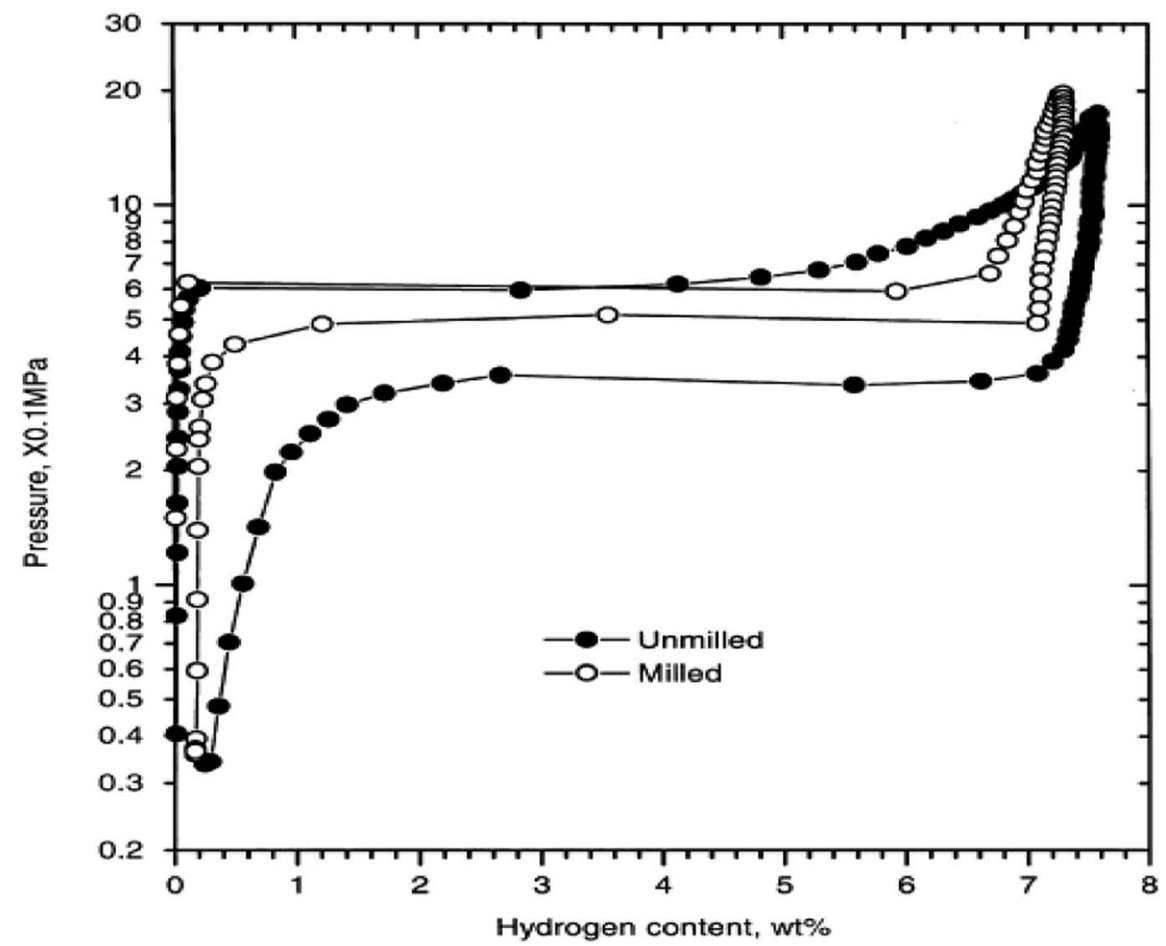

Fig. 3 Pressure-composition-temperature (PCT) curves of the unmilled and ball-milled $\mathrm{MgH}_{2}$ at $623 \mathrm{~K}^{25}$

indicating very fast desorption kinetics due to the novel nanostructures with a high surface area caused by ball milling $(\mathrm{BM}){ }^{25}$

Currently, the mechanochemical synthesis of metal hydrides using RMM has become one of the most frequently used methods. Generally, mill machines can be classified into four categories: planetary, rotational, vibratory and attritor mills. ${ }^{15}$ Considering the final products expected from BM, several milling parameters can be varied in the ball-milling synthesis, including the type of milling bowl and ball, milling speed, milling time, ball-to-powder weight ratio, milling atmosphere, pressure of the selected gas, temperature of milling, and process control agents to inhibit particle agglomeration. Varin et al. ${ }^{26}$ investigated the effect of ball milling time on the particle and grain/crystallite size and clearly showed that a particle size reduction occurs within a very similar time frame as the reduction in grain size (Fig. 4). Besides Jain et al. ${ }^{23}$ systematically investigated the role of ball milling in improving the surface and kinetic properties in the preparation of Mg-based alloys. They concluded that the pulverization and deformation processes during high energy ball milling play a major role in the hydriding reaction. Thus far, RMM under hydrogen gas
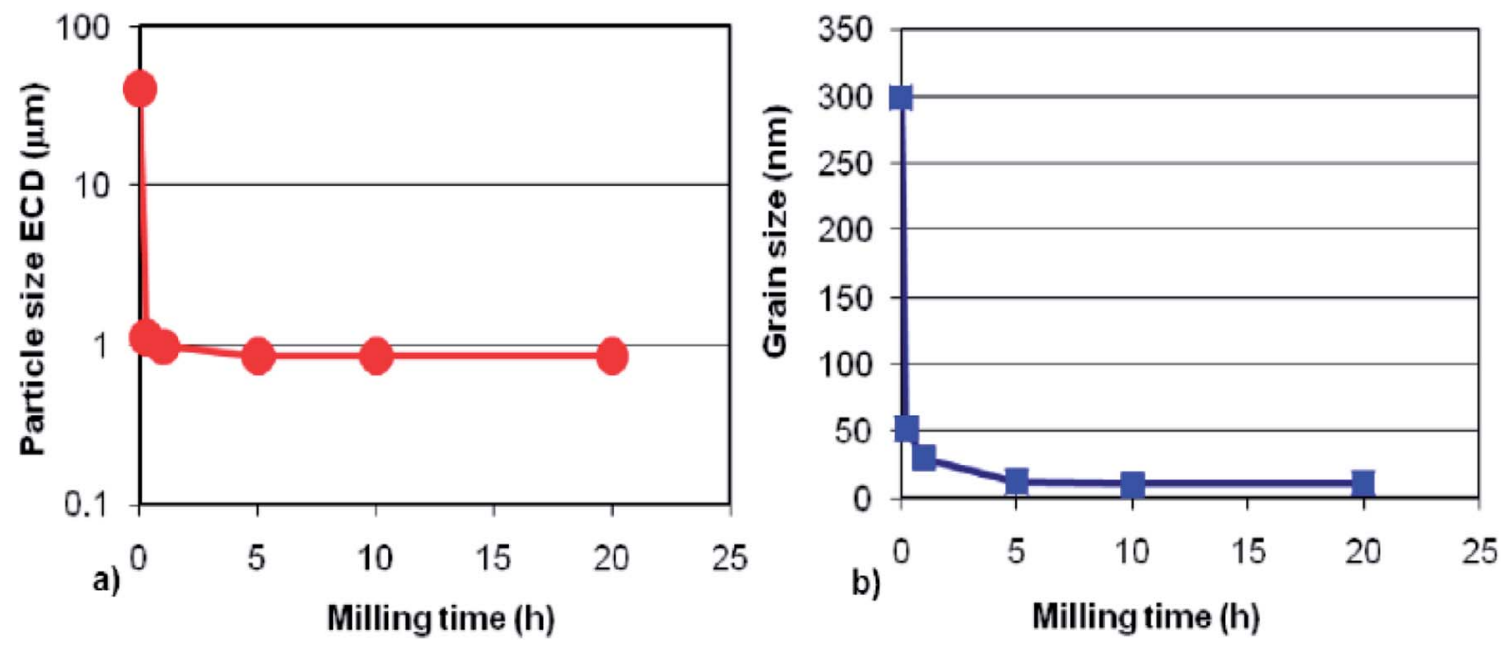

Fig. 4 Simultaneous reduction in the (a) particle size and (b) grain size as a function of ball milling time of $\mathrm{MgH}_{2}{ }^{26}$ 
allows the synthesis of binary and ternary metal hydrides $(\mathrm{Mg}-$ $\mathrm{Fe}-\mathrm{H}, \mathrm{Mg}-\mathrm{Co}-\mathrm{H}, \mathrm{Mg}-\mathrm{Ni}-\mathrm{H}, \mathrm{Mg}-\mathrm{Ti}-\mathrm{H})$, Mg-based complex hydrides and alanates. ${ }^{27}$ However, the preparation of such small particles by ball milling on a large scale is a major challenge.

\section{Approaches to modify the thermodynamics of $\mathrm{Mg} / \mathrm{MgH}_{2}$ systems}

As mentioned before, the stable thermodynamics of $\mathrm{MgH}_{2}$ is the major obstacle in its practical application. According to the van't Hoff equation, we can conclude that changing the enthalpy and entropy of the hydrogenation reaction is an efficient way to decrease the desorption temperature of $\mathrm{Mg} / \mathrm{MgH}_{2}$ systems. Considering that changing the entropy has little effect on metal hydrogen systems, decreasing the enthalpy change for the reaction is the basic guideline for decreasing the desorption temperature of $\mathrm{Mg} / \mathrm{MgH}_{2}$ systems. In this section, we present the strategies for modifying the thermodynamics of $\mathrm{MgH}_{2}$, such as alloying, nanostructuring, metastable phase formation and changing the reaction path.

\subsection{Alloying}

Generally, hydrogen storage alloys consist of a high temperature hydride forming element $\mathrm{A}$ and a non-hydride forming element B (Fig. 5).$^{28}$ If Mg-based alloys are made with a hydride nonforming element and form less stable hydrides to destabilize the hydrogenated state, the hydriding reaction enthalpy can be remarkably decreased. Therefore, alloying is a traditional but effective strategy for altering the thermodynamics of $\mathrm{Mg}$-based alloys.

4.1.1 Intermetallic compounds. A classic example of alloying is the $\mathrm{Mg}_{2} \mathrm{NiH}_{4}$ compound, which was first reported by Reilly in 1968. $\mathrm{Mg}_{2} \mathrm{Ni}$ is also a potential hydrogen storage material owing to its high hydrogen storage capacity of $3.6 \mathrm{wt} \% .^{29,30}$ Since the $\mathrm{Ni}-\mathrm{H}$ interaction in $\mathrm{Mg}_{2} \mathrm{NiH}_{4}$ is much

\section{A: hydride forming element; $\mathbf{B}$ : non hydride forming element}
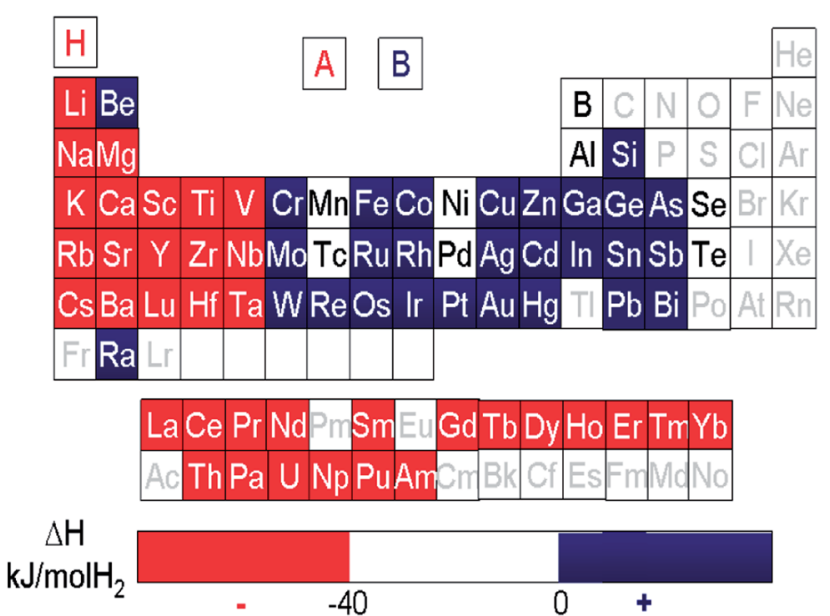

Fig. 5 Hydride and non-hydride forming elements in the periodic table of elements. ${ }^{28}$ weaker than that in pure $\mathrm{MgH}_{2}, \mathrm{Mg}_{2} \mathrm{NiH}_{4}$ has an enthalpy of formation of around $-64 \mathrm{~kJ} \mathrm{~mol}^{-1} \mathrm{H}_{2}$, which means that its desorption temperature is around $523 \mathrm{~K}$ with a plateau pressure of around 3.4 bar at room temperature. $\mathrm{Mg}_{2} \mathrm{Ni}$ was further studied by applying the element substitution method to further decrease its enthalpy of hydrogen absorption and desorption. Hou et al. reported an improvement in the enthalpy of formation of $\mathrm{Mg}_{2}$ Ni-type alloys by introducing a fraction of $\mathrm{Zn}$ or Ti in place of $\mathrm{Mg}$, such as $\mathrm{Mg}_{1.875} \mathrm{Zn}_{0.125} \mathrm{NiH}_{4}$ with an enthalpy of formation of $-53.43 \mathrm{~kJ} \mathrm{~mol}^{-1} \mathrm{H}_{2} \cdot{ }^{31}$ Another interesting finding is that $\left(\mathrm{Mg}_{1-x} \mathrm{Ca}_{x}\right) \mathrm{Ni}_{2}$-based alloys can desorb hydrogen at room temperature and the hydride formation enthalpy and entropy of $\left(\mathrm{Mg}_{0.68} \mathrm{Ca}_{0.32}\right) \mathrm{Ni}_{2}$ were determined to be $\Delta H=-37 \mathrm{~kJ}\left(\mathrm{~mol}^{-1}\right.$ $\left.\mathrm{H}_{2}\right)$ and $\Delta S=-94 \mathrm{~J}\left(\mathrm{~K}^{-1} \mathrm{~mol}^{-1} \mathrm{H}_{2}\right)$, respectively. Unfortunately, with a decrease in its $\mathrm{Mg}$ content, its hydrogen storage capacity decreased to $1.4 \mathrm{wt} \% .^{32}$

Similarly to the $\mathrm{Mg}-\mathrm{Ni}$ system, $\mathrm{Mg}$ and $\mathrm{Cu}$ can form the $\mathrm{Mg}_{2} \mathrm{Cu}$ alloy. Upon the application of $30 \mathrm{MPa}$ hydrogen pressure to $\mathrm{Mg}_{2} \mathrm{Cu}$, it decomposes to $\mathrm{MgH}_{2}$ and $\mathrm{MgCu}_{2}$ according to the following disproportionation reaction (2):

$$
2 \mathrm{Mg}_{2} \mathrm{Cu}+\mathrm{H}_{2} \rightarrow 3 \mathrm{MgH}_{2}+\mathrm{MgCu}_{2}
$$

The hydride formation enthalpy and entropy of reaction (2) is $-73.5 \mathrm{~kJ}\left(\mathrm{~mol}^{-1} \mathrm{H}_{2}\right)$ and $-146 \mathrm{~J}\left(\mathrm{~K}^{-1} \mathrm{~mol}^{-1} \mathrm{H}_{2}\right)$, respectively, with a hydrogen capacity of $2.6 \mathrm{wt} \%,{ }^{33}$ and the equilibrium temperature for 1 bar hydrogen pressure is reduced to about $513 \mathrm{~K}$. Unfortunately, this reaction is irreversible. Advanced research has shown that $\mathrm{Mg}-\mathrm{Cu}-\mathrm{H}$ nanoparticle systems can further reduce the hydride formation enthalpy and entropy to $-67.5 \mathrm{~kJ}\left(\mathrm{~mol}^{-1} \mathrm{H}_{2}\right)$ and $-124.4 \mathrm{~J}\left(\mathrm{~K}^{-1} \mathrm{~mol}^{-1} \mathrm{H}_{2}\right)$, respectively. ${ }^{34}$ Thus from the above research, we can preliminarily conclude that nanostructuring of $\mathrm{Mg}$-based alloys provides a potential strategy to further alter their thermodynamic properties without loss in their hydrogen capacity.

Normally, $\mathrm{Mg}$ and Fe are immiscible, but the ternary hydride $\mathrm{Mg}_{2} \mathrm{FeH}_{6}$ can be formed in the presence of hydrogen by mechanical milling. The hydride formation enthalpy and entropy are $-77.9 \mathrm{~kJ}\left(\mathrm{~mol}^{-1} \mathrm{H}_{2}\right)$ and $-140 \mathrm{~J}\left(\mathrm{~K}^{-1} \mathrm{~mol}^{-1} \mathrm{H}_{2}\right)$, respectively. Furthermore, it has a gravimetric storage capacity of $5.6 \mathrm{wt} \%$ and the highest known volumetric hydrogen density, amounting to $150 \mathrm{~kg} \mathrm{~m}^{-3}$, which is more than double that of liquid hydrogen at $20.2 \mathrm{~K}$ and moderate pressures up to 20 bar. $^{35}$ The theoretical research conducted by Batalovic ${ }^{36}$ demonstrated the influence of transition metal ( $\mathrm{Ni}, \mathrm{Co}$, and $\mathrm{Mn}$ ) doping on the hydrogen sorption properties of $\mathrm{Mg}_{2} \mathrm{FeH}_{6}$. They found that the largest decrease in desorption enthalpy was in the case of nickel doping, resulting in a $27.7 \mathrm{~kJ}\left(\mathrm{~mol}^{-1} \mathrm{H}\right)$ energy change. Similarly to the $\mathrm{Mg}-\mathrm{Fe}$ system, reactive ball-milling of $\mathrm{Mg}$ and Co under hydrogen gas led to the formation of $\mathrm{Mg}_{2} \mathrm{CoH}_{5}$ with the gravimetric storage capacity of $4.5 \mathrm{wt} \%$, hydride formation enthalpy of $-82 \mathrm{~kJ} \mathrm{~mol}^{-1} \mathrm{H}_{2}$ and desorption temperature for 1 bar hydrogen pressure of about $513 \mathrm{~K}^{.37}$ It is important to highlight that the formation of $\mathrm{Mg}_{2} \mathrm{FeH}_{6}$ consists of two steps that always involve $\mathrm{MgH}_{2}$ as a precursor, which was also confirmed by the in situ hydrogen uptake curve (Fig. 6) monitored during the synthesis of $\mathrm{Mg}_{2} \mathrm{TM}(\mathrm{TM}=\mathrm{Fe}$ and Co) 


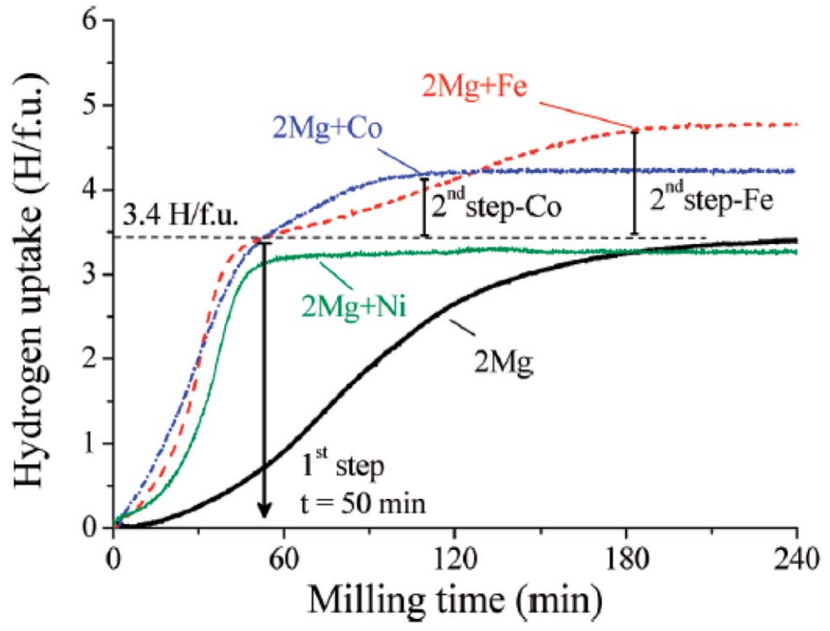

Fig. 6 Absorbed hydrogen atoms by formula unit of the formed hydride during RBM of $\mathrm{Mg}$ and $\mathrm{Mg}^{+2} \mathrm{TM}$ mixtures ( $\mathrm{TM}=\mathrm{Ni}$, Fe, and $\mathrm{Co}$ ) (The number of absorbed $\mathrm{H}$ atoms per unit metal or alloy formula $(\mathrm{H} /$ f.u.)). ${ }^{38}$

hydrides according to reaction $(3) ;{ }^{38}$ whereas, a unique absorption step was detected in the case of $\mathrm{Ni}^{39}$

$$
2 \mathrm{Mg}+\mathrm{TM}+\frac{x}{2} \mathrm{H}_{2} \rightarrow 2 \mathrm{MgH}_{2}+\mathrm{TM}+\frac{x-4}{2} \mathrm{H}_{2} \rightarrow \mathrm{Mg}_{2} \mathrm{TMH}_{x}
$$

(for $\mathrm{Fe}, \mathrm{Co}, x=6,5$ )

4.1.2 Mg-based solid solution. Forming an Mg-based solid solution is another destabilization strategy, which can apply a minor modulation to the structure and composition of $\mathrm{Mg}$ with an acceptable loss in capacity, thus probably altering its thermodynamic stability. Cadmium is the only element exhibiting unlimited solubility in $\mathrm{Mg}$ in the solid state. Douglass et $a .^{40}$ first reported the $\mathrm{Mg}-1$ at\% Cd alloy, which can absorb $5 \mathrm{wt} \%$ hydrogen at $673 \mathrm{~K}$ in $24 \mathrm{~h}$. Schulz performed a more detailed study of the hydrogenation kinetics and thermodynamics of Mg- $x$ at $\% \mathrm{Cd}(x=5,10$, and 20$)$, which could be activated for hydrogen absorption even after annealing at $523 \mathrm{~K}$ for $24 \mathrm{~h}$ under the hydrogen pressure of $1.5 \mathrm{MPa} .^{41}$ However, Skripnyuk et al. prepared $\mathrm{Mg}_{3} \mathrm{Cd}$ alloys using high energy milling, which exhibited a reversible hydrogen storage capacity of $2.8 \mathrm{wt} \%$ and could quickly absorb $2.5 \mathrm{wt} \%$ hydrogen at $573 \mathrm{~K}$ in $120 \mathrm{~s}$. As shown in Fig. 7, no measurable pressure hysteresis was observed from the PCT, and the formation enthalpy of the hydride is $-65.5 \mathrm{~kJ} \mathrm{~mol}^{-1}$. $^{42}$

According to the binary phase diagram of the Mg-In system, it has a high solubility of up to 10 at $\%$ indium in a wide temperature range. ${ }^{43}$ The $\mathrm{Mg}$ (In) solid solution absorbs hydrogen to form $\mathrm{MgH}_{2}$ and a disordered $\mathrm{Mg}$-In compound. Table 3 summaries the lattice constants and hydrogen storage properties of $\mathrm{Mg}$ (In) solid solutions. The $\mathrm{Mg}_{0.95} \mathrm{In}_{0.05}$ solid solution can reversibly react with hydrogen at $573 \mathrm{~K}$ according to the following reaction (4):

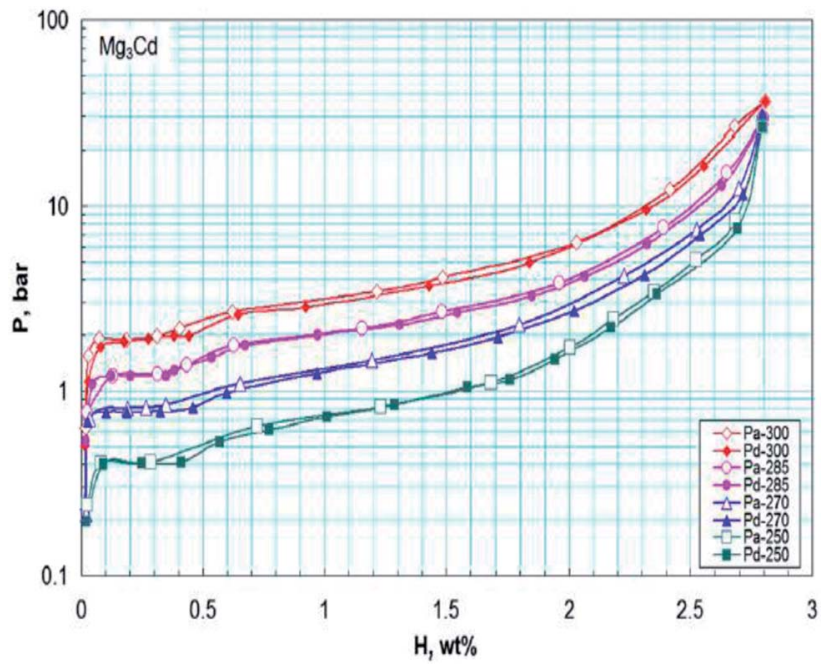

Fig. $7 \mathrm{PCT}$ diagrams of the studied $\mathrm{Mg}_{3} \mathrm{Cd}$ alloy in the temperature range of $250-300{ }^{\circ} \mathrm{C}$. The open and filled symbols correspond to the absorption and desorption branches of the curves, respectively. ${ }^{42}$

$$
\mathrm{Mg}_{95} \mathrm{In}_{5}+0.9 \mathrm{H}_{2} \leftrightarrow 0.9 \mathrm{MgH}_{2}+0.05 \mathrm{MgIn}
$$

The hydrogen storage capacity of $\mathrm{Mg}_{0.95} \mathrm{In}_{0.05}$ is about $5.3 \mathrm{wt} \%$, but the poor kinetics of its desorption/absorption reaction is a key problem. ${ }^{44}$ Thus, Zhu et al. conducted research on $\mathrm{Mg}$-based solid solutions, including $\mathrm{Mg}$ (In, $\mathrm{Al}$ ), $\mathrm{Mg}$ (In, Cd) and $\mathrm{Mg}$ (In, Y) ternary alloys. Compared with the binary $\mathrm{Mg}$ (Al) solid solution, the $\mathrm{Mg}$ (In, Al) ternary solid solution presented improved dehydriding reversibility and a substantial decrease in $\Delta H$ because $\mathrm{Al}$ was dissolved in the $\beta$ phase. ${ }^{45}$

With respect to the Mg-In-Y ternary system, the reversible dissolving of $\mathrm{Y}$ in $\mathrm{Mg}$ was realized by the decomposition of the $\mathrm{In}_{3} \mathrm{Y}$ phase in dehydriding, but the reversible solubility of $\mathrm{Y}$ is rather low due to the formation of $\mathrm{YH}_{2}$. The $\mathrm{Mg}_{90} \mathrm{In}_{5} \mathrm{Y}_{5}$ solid solution exhibited a decreased reaction enthalpy of $62.9 \mathrm{~kJ}$ $\left(\mathrm{mol}^{-1} \mathrm{H}_{2}\right)$, which was reduced by $5 \mathrm{~kJ}\left(\mathrm{~mol}^{-1} \mathrm{H}_{2}\right)$ and $12 \mathrm{~kJ}$ $\left(\mathrm{mol}^{-1} \mathrm{H}_{2}\right.$ ) compared to that of the $\mathrm{Mg}_{95} \mathrm{In}_{5}$ binary solid solution and pure $\mathrm{Mg}$, respectively. ${ }^{46}$ Similarly to the $\mathrm{Mg}-\mathrm{In}-\mathrm{Y}$ system, the hydriding reaction of the $\mathrm{Mg}_{90} \mathrm{In}_{5} \mathrm{Cd}_{5}$ alloy can be described as reaction (5):

$$
\mathrm{Mg}_{90} \mathrm{In}_{5} \mathrm{Cd}_{5}+70 \mathrm{H}_{2} \leftrightarrow 70 \mathrm{MgH}_{2}+5 \mathrm{MgIn}+5 \mathrm{Mg}_{3} \mathrm{Cd}
$$

The dehydriding reaction enthalpy $\Delta H$ and entropy $\Delta S$ for the $\mathrm{Mg}_{90} \mathrm{In}_{5} \mathrm{Cd}_{5}$ alloy are $86.0 \mathrm{~kJ}\left(\mathrm{~mol}^{-1} \mathrm{H}_{2}\right)$ and $154.8 \mathrm{~J}\left(\mathrm{~K}^{-1}\right.$ $\mathrm{mol}^{-1} \mathrm{H}_{2}$ ), respectively. The PCT results showed a reversible hydrogen storage capacity of $4.3 \mathrm{wt} \%$ and elevated equilibrium pressure for the $\mathrm{MgH}_{2}$ in the $\mathrm{Mg}_{90} \mathrm{In}_{5} \mathrm{Cd}_{5}$ alloy compared with pure $\mathrm{MgH}_{2}$ (Fig. 8). The $\mathrm{Mg}_{90} \mathrm{In}_{5} \mathrm{Cd}_{5}$ alloy also exhibited enhanced hydrogenation kinetics with a decreased hydrogenation activation energy of $61.0 \mathrm{~kJ} \mathrm{~mol}^{-1}$, but its dehydrogenation rate is slow due to the long-range diffusion of $\mathrm{In}$ and $\mathrm{Cd}$ in $\mathrm{MgH}_{2}{ }^{47} \mathrm{Mg}$-based solid solutions can reduce the reaction enthalpy with a higher hydrogen capacity than the $\mathrm{Mg}-\mathrm{Ni}$ alloy 
Table 3 Lattice constants of $\mathrm{Mg}$-based solid solutions and their hydrogen storage properties ${ }^{44}$

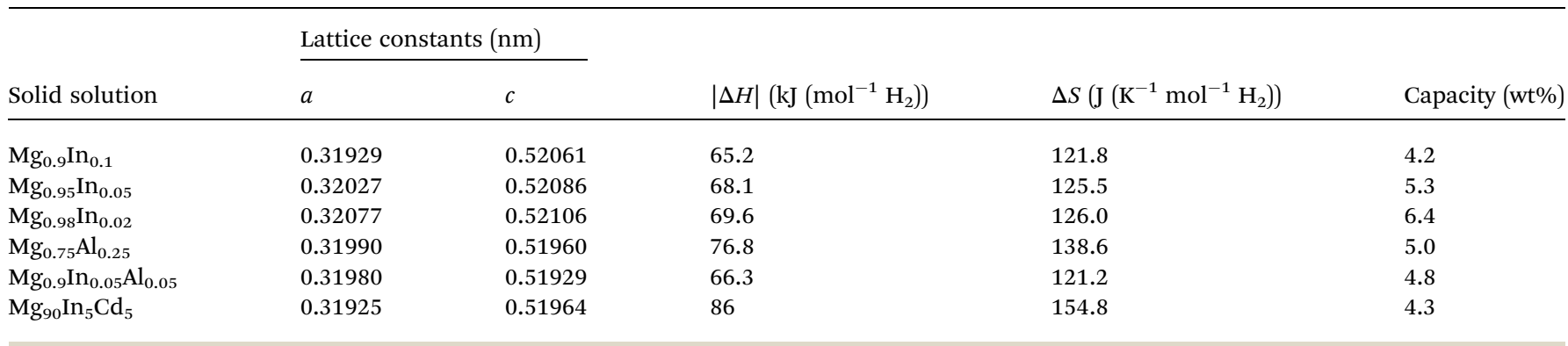

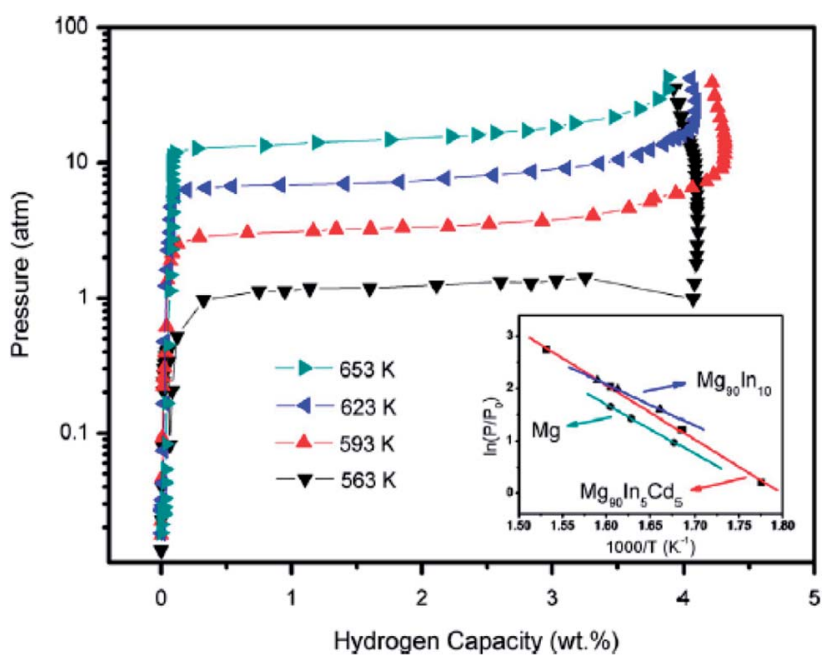

Fig. 8 PCT and van't Hoff plot (the inset) for the hydrogen desorption of the $\mathrm{Mg}_{90} \mathrm{In}_{5} \mathrm{Cd}_{5}$ alloy. ${ }^{47}$

and even can compete with the $\mathrm{Mg}-\mathrm{Fe}$ alloy in terms of hydrogen capacity, but their sluggish kinetics is still an issue.

Generally, alloying is a feasible way to modify the thermodynamics of $\mathrm{Mg}$-base hydrogen storage alloys. However, there still exists some disadvantages, such as the hydrogen capacity decreases sharply after alloying due to the introduction of heavy metals and most of these Mg-base alloys still suffer from poor reversibility because the bonds between $\mathrm{Mg}$ and the other element break during the process of hydrogenation. Besides, $\mathrm{Mg}-\mathrm{Fe}, \mathrm{Mg}-\mathrm{Co}$, and $\mathrm{Mg}$ (In, Cd) present a higher $\Delta H$ for the dehydrogenation reaction than $\mathrm{Mg} / \mathrm{MgH}_{2}$; thus further research should be performed to address their remaining problems.

\subsection{Nanostructuring}

A major feature that discriminates various types of nanostructures is the dimensionality of their architecture, for example, zero-dimensional (0D; such as nanoparticles (NPs), quantum dots, and hollow spheres), one-dimensional (1D; such as nanowires, nanofibers, nanorods and nanobelts), twodimensional (2D; such as thin films and nanosheets), and three-dimensional (3D; such as frameworks, nanoflowers, and dendritic structures), as demonstrated in Fig. 9.8 ${ }^{48}$ Nanomaterials exhibit numerous advantages for batteries, fuel cells, and hydrogen storage systems. For example, with the decreasing size of a material, its surface-to-volume ratio increases apparently. Moreover, the atoms on the surface may have some dangling bonds, which are extremely active and tend to form bonds with surrounding molecules to reduce the surface energy. Thus, reducing the particle and grain size of $\mathrm{Mg}$ based materials is a promising way to further decrease their hydride formation enthalpy $\Delta H$.

4.2.1 Nanoparticles or nanocrystalline material. For particles of sufficiently small size, the surface energy terms cannot be ignored. In the particular case of hydrogen desorption from $\mathrm{MgH}_{2}$, the inclusion of these surface energy terms gives a new van't Hoff reaction (6) as follows: ${ }^{49}$

$$
\ln \frac{p_{\text {nano }}^{\text {eq }}}{p^{\theta}}=\frac{1}{\mathrm{RT}}\left[\Delta H^{\theta}+\left(\frac{3 V_{\mathrm{Mg}} \gamma_{\mathrm{Mg}}}{r_{\mathrm{Mg}}}-\frac{3 V_{\mathrm{MgH}_{2}} \gamma_{\mathrm{MgH}_{2}}}{r_{\mathrm{MgH}_{2}}}\right)\right]-\frac{\Delta S^{\theta}}{R}
$$

Bulk $\mathrm{MgH}_{2}$ is destabilised when the contribution related to size becomes sufficiently negative, i.e. the surface energy density of $\mathrm{MgH}_{2}$ is significantly larger than that of magnesium, and some of the heat of formation will be stored as excess surface energy, which will reduce the heat released upon hydride formation and hydrogen release. Wagemans et al. predicted a considerable reduction $(>10 \%)$ in $\Delta H$ for radii smaller than $4 \mathrm{~nm}$, while DFT calculations predicted a result below $2 \mathrm{~nm}$. The calculations showed that $\mathrm{MgH}_{2}$ is more destabilized than $\mathrm{Mg}$ upon decreasing the cluster size below $19 \mathrm{Mg}$ atoms (Fig. 10). For instance, an $\mathrm{Mg}_{9} \mathrm{H}_{18}$ cluster size of $0.9 \mathrm{~nm}$ corresponds to a desorption temperature of only $473 \mathrm{~K}$ with an enthalpy formation of $-63 \mathrm{~kJ} \mathrm{~mol}^{-1} \mathrm{H}_{2}{ }^{50} \mathrm{Liu}$ et al. successfully synthesized $\mathrm{Mg}$ nanoparticles by reducing di- $n$-butyl magnesium with lithium in the presence of naphthalene as an electron carrier. Further determination of the hydrogen thermodynamics of these materials revealed a significant evolution in both enthalpy and entropy with a decrease in particle sizes

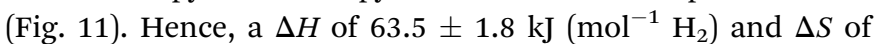
$118.4 \pm 3.1 \mathrm{~J}\left(\mathrm{~K}^{-1} \mathrm{~mol}^{-1} \mathrm{H}_{2}\right)$ were measured for $\mathrm{MgLi}_{4.6} \mathrm{Napth}_{0.5}$ with an average particle size of $16 \mathrm{~nm} .^{.51}$

Recently, there have been numerous methods reported for the preparation of $\mathrm{MgH}_{2} \mathrm{NPs}$, including ball milling, hybrid combustion, melt spinning, and chemical vapour deposition (CVD). The nanostructured uniform mixture of $\mathrm{MgH}_{2}-0.1 \mathrm{TiH}_{2}$ powder is a reversible hydrogen storage material with a cyclic hydrogen storage capacity of $6 \mathrm{wt} \%$, which demonstrated good 


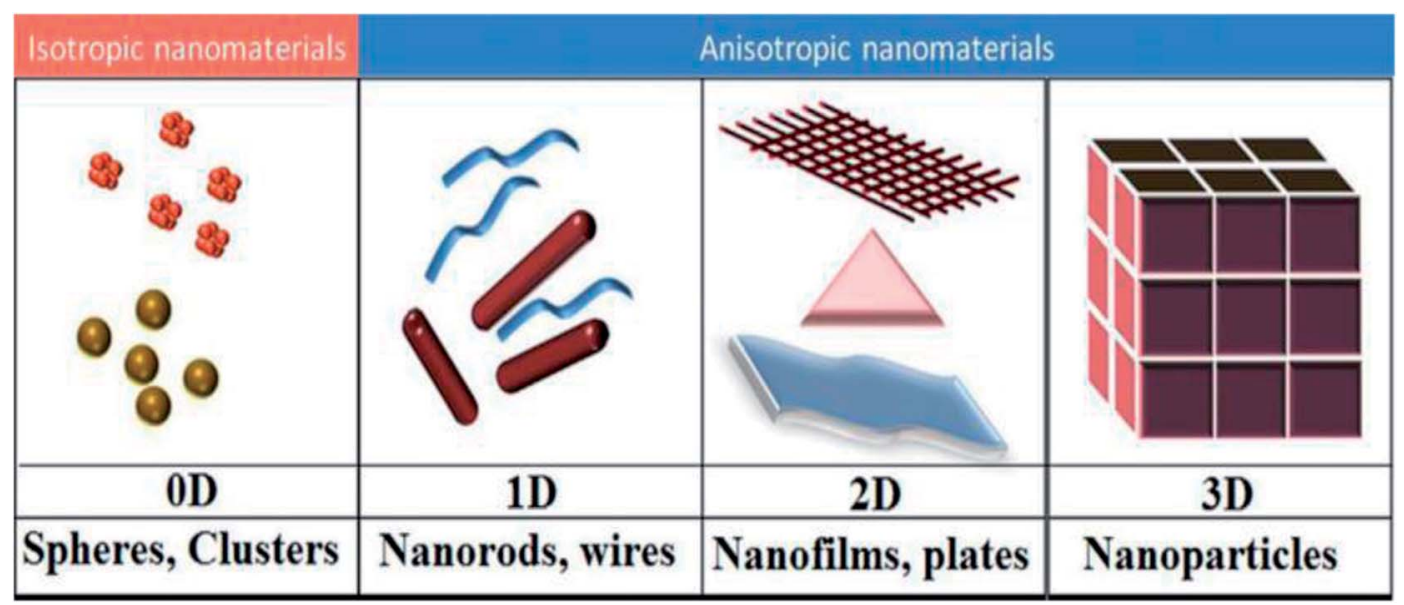

Fig. 9 Schematic representation of the various dimensions (OD, 1D, 2D, and 3D) of nanomaterials. ${ }^{48}$

cycling stability with no loss in capacity over 80 cycles. The $\Delta H$ for the dehydrogenation of $\mathrm{MgH}_{2}-0.1 \mathrm{TiH}_{2}$ is $68 \mathrm{~kJ}\left(\mathrm{~mol}^{-1} \mathrm{H}_{2}\right)$, which is lower than that for $\mathrm{MgH}_{2}\left(75 \mathrm{~kJ}\left(\mathrm{~mol}^{-1} \mathrm{H}_{2}\right)\right)$. This can be attributed to two factors, its nanosize and the addition of $\mathrm{TiH}_{2} \cdot{ }^{52}$ Besides, Asano et al. ${ }^{53}$ demonstrated clearly that embedding $\mathrm{Mg}$ nanometer-sized clusters in a matrix of immiscible metals is a powerful strategy to destabilize $\mathrm{MgH}_{2}$, resulting in a lower working temperature for hydrogen storage applications. Carbon-based materials also show huge potential in improving the hydrogen storage performance of $\mathrm{MgH}_{2}$. Several works have been devoted to combining $\mathrm{MgH}_{2}$ with various carbon materials, for example, nanocomposite ( $\mathrm{Mg}-$ V) nano/G exhibits a reversible hydrogen capacity of $6.03 \mathrm{wt} \%$

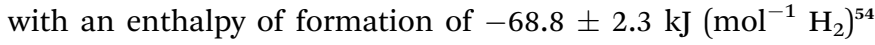
and the magnesium particles with a carbon additive were milled to 20-60 nm with enthalpy and entropy changes of $44.5 \mathrm{~kJ}$ $\left(\mathrm{mol}^{-1} \mathrm{H}_{2}\right)$ and $83.8 \mathrm{~J}\left(\mathrm{~K}^{-1} \mathrm{~mol}^{-1} \mathrm{H}_{2}\right)$, respectively according to Fig. $12 .{ }^{55}$ Graphite and carbon as a process control agent (PCA)

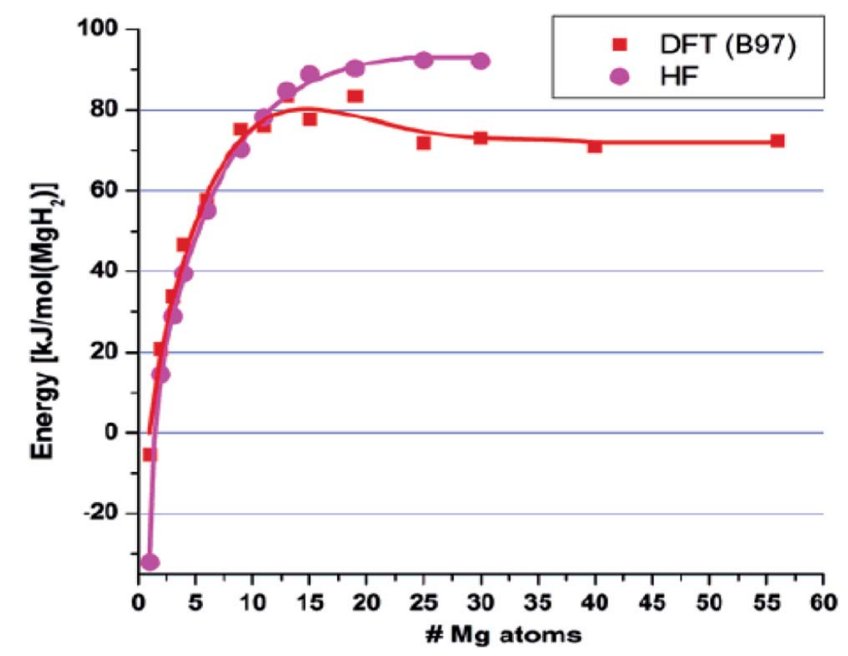

Fig. 10 Calculated desorption energies for $\mathrm{MgH}_{2}$ clusters using both the HF method and DFT method (B97 functional). The energies were normalized per mole of $\mathrm{H}_{2}$ released. ${ }^{50}$ can reduce the agglomeration of the milled particles, and thus allow better particle refinement by stabilizing the surface charges created at the fresh surfaces of the fractured particles. In summary, it has been clearly demonstrated that the use of carbon materials offers many opportunities in tailoring the properties of metal hydrides. Since their porosity and surface chemistry can be adjusted in a broad range, their use as a support shows great potential for further improvements in hydrogen storage applications.

The formation of a nanocrystalline structure and associated defects through mechanical milling is often perceived as leading to enhanced hydrogen kinetics. Similarly to the case of surfaces discussed above, grain boundaries between nanocrystals contain excess energy, resulting in surface energy, thus providing another potential tool for reducing the formation enthalpy of metal hydrides. Calizzi et al. ${ }^{56}$ prepared $\mathrm{Mg}-\mathrm{Ti}$ nanostructured samples with a metastable $\mathrm{Mg}-\mathrm{Ti}-\mathrm{H}$ fcc phase and the mean crystallite size of $\mathrm{Mg}$ and $\beta-\mathrm{MgH}_{2}$ decreased with an increase in Ti content (Fig. 13). However, their results only

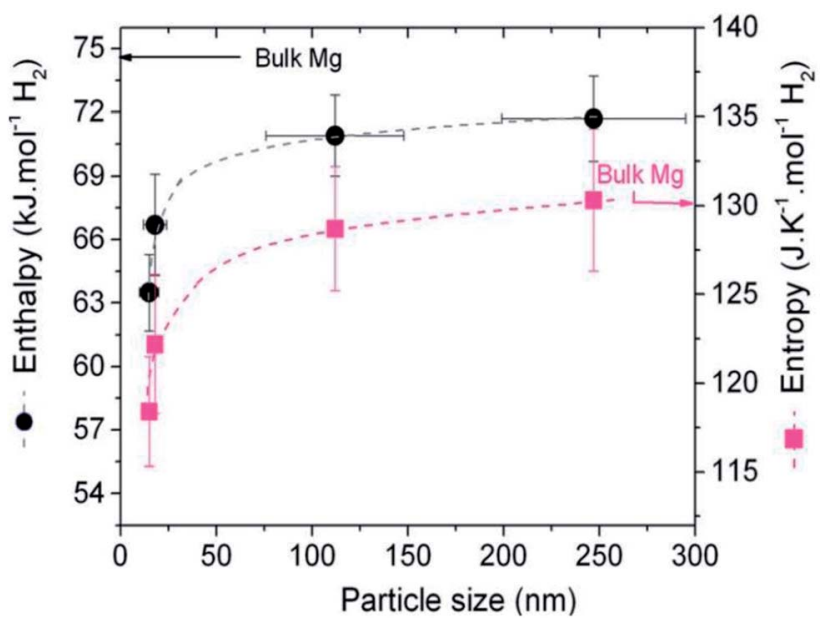

Fig. 11 Evolution of $\Delta H$ and $\Delta S$ versus size of the magnesium nanoparticles. The dotted line is a guide to the eyes. ${ }^{51}$ 


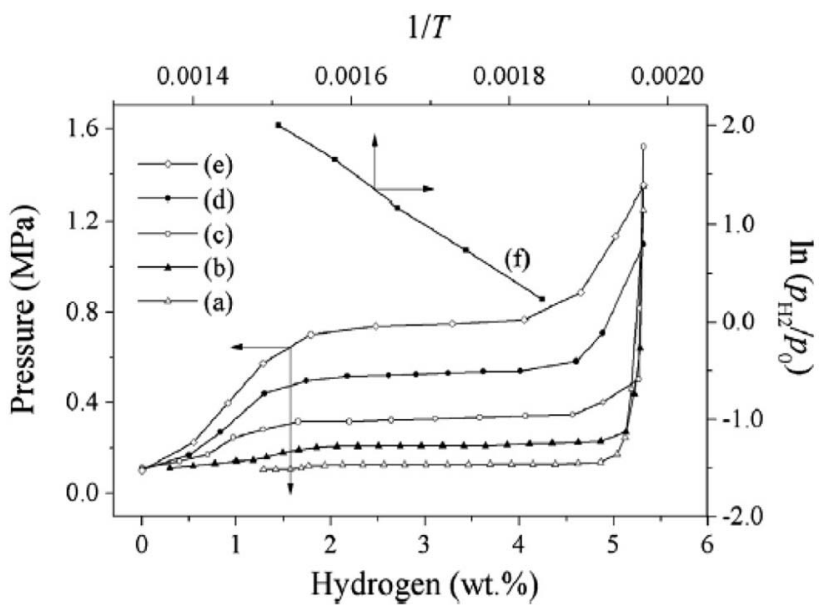

Fig. 12 Dehydrogenation isotherms of the material from $\mathrm{Mg}$ and $\mathrm{C}$ in a ratio of $70: 30$, milled for $3 \mathrm{~h}$ under $1 \mathrm{MPa} \mathrm{H}_{2}$ at $543 \mathrm{~K}(\mathrm{a}), 573 \mathrm{~K}$ (b), $603 \mathrm{~K}(\mathrm{c}), 633 \mathrm{~K}(\mathrm{~d})$, and $663 \mathrm{~K}(\mathrm{e})$, and plot of $\ln \left(P_{\mathrm{H}_{2}} / P_{0}\right)$ versus $1 / T(\mathrm{f}){ }^{55}$

showed an enhanced kinetic properties in the Mg-Ti system since the modification in thermodynamics due to interface energy effects or coherency strain may be too small to be detected. Further research showed that the hydriding enthalpy of Mg-Fe-based materials with a crystallite size of $10 \mathrm{~nm}$ decrease by $6 \mathrm{~kJ}\left(\mathrm{~mol}^{-1} \mathrm{H}_{2}\right)$ between $523 \mathrm{~K}$ and $673 \mathrm{~K}$ (ref. 57) and an $\mathrm{La}_{2} \mathrm{Mg}_{17}-\mathrm{LaNi}_{5}$ nanocrystalline composite material had a lower enthalpy of $-53.23 \mathrm{~kJ}\left(\mathrm{~mol}^{-1} \mathrm{H}_{2}\right) .^{58}$

Although the surface energy, lattice strain and defects, and excess enthalpy in the grain boundaries provide effective ways to lower the enthalpy of formation without loss in hydrogen storage capacity, they are usually unstable since the excess enthalpy will increase the free energy and drive recrystallization. Nanocrystalline $\mathrm{MgH}_{2}$ resulting from ball milling undergoes a significant growth in crystallite size or subsequent structural relaxation of defects upon the very first hydrogen cycle, which sluggishly decreases the advantages of

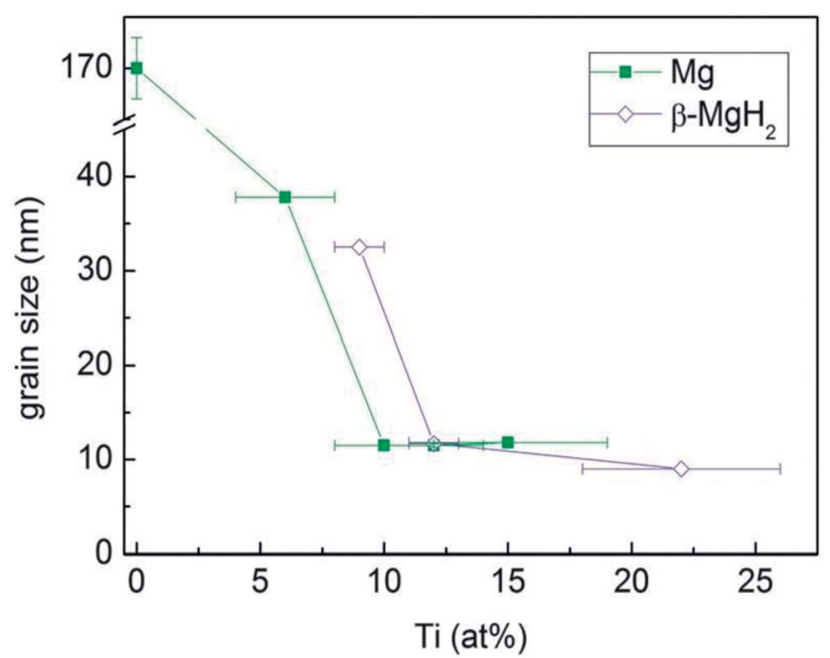

Fig. 13 Mean crystallite size of the $\mathrm{Mg}$ and $\beta-\mathrm{MgH}_{2}$ phases in the $\mathrm{Mg}-$ $\mathrm{Ti}$ and $\mathrm{Mg}-\mathrm{Ti}-\mathrm{H}$ samples as a function of Ti content. ${ }^{56}$ nanocrystallization. Therefore, finding a proper way to protect NPs from aggregation or recrystallization is urgent.

4.2.2 Nanowires and nanofiber. Li et al. ${ }^{59}$ prepared different $\mathrm{Mg}$ nanowires via a vapor-transport approach, with a diameter in the range of 30-50 nm (S1) (Fig. 14(a, b, g, h, and i)) and $80-100 \mathrm{~nm}(S 2)$, which appeared to be tangled together and have a zigzag morphology (Fig. 14(c and d)), and short and rod-like structures of $\mathrm{Mg}$ with a diameter in the range of 150$170 \mathrm{~nm}(S 3)$ (Fig. 14(e and f)). The calculated $\Delta H$ values for the dehydriding of the $S 1, S 2$, and $S 3$ hydrides were 65.3, 65.9, and $67.2 \mathrm{~kJ}\left(\mathrm{~mol}^{-1} \mathrm{H}_{2}\right)$, respectively. It is apparent that the $\mathrm{Mg}$ nanowires with thinner diameters have the advantage of easy activation for hydrogen absorption/desorption (Fig. 14(j and k)). The presented results showed that thinner $\mathrm{Mg} / \mathrm{MgH}_{2}$ nanowires have a much lower desorption energy than that of thicker nanowires or bulk $\mathrm{Mg} / \mathrm{MgH}_{2}$, indicating that changes in thermodynamics are expected if the diameters of the nanowires are thinner than $30 \mathrm{~nm}$.

They further studied the size effects on the thermodynamic stability of $\mathrm{MgH}_{2}$ nanowires as well as the size dependency on the energetic stability of magnesium and $\mathrm{MgH}_{2}$ nanowires using first-principles density functional theory. ${ }^{60}$ The desorption enthalpy, $\Delta H_{\text {des }}$, was calculated to be $-20.64,34.54$, and $61.86 \mathrm{~kJ}\left(\mathrm{~mol}^{-1} \mathrm{H}_{2}\right)$ for the nanowires of A1_ $\mathrm{MgH}_{2}(\varphi 0.68 \mathrm{~nm})$, $\mathrm{A} 2 \_\mathrm{MgH}_{2}(\varphi 0.85 \mathrm{~nm})$, and $\mathrm{A}_{-} \_\mathrm{MgH}_{2}(\varphi 1.24 \mathrm{~nm})$, as shown in Fig. 15. Thus, we can conclude that a decrease in diameter leads to energetic instability in $\mathrm{MgH}_{2}$ and magnesium nanowires; however, $\mathrm{MgH}_{2}$ nanowires are more strongly destabilized than magnesium nanowires, which result in the thermodynamic destabilization of $\mathrm{MgH}_{2}$ nanowires as their diameter decreases. Accordingly, the nanowire structured $\mathrm{Mg}$ can be considered as a promising hydrogen storage material due to its thermodynamic destabilization.

4.2.3 Nanofilms. Compared with other methods, 2D thin film fabrication provides a promising approach to achieve accurate control of the nanostructure, composition, and interfacial properties of hydrogen storage materials by accurately tailoring on the nanoscale. Consequently, thin films have been extensively applied in Mg-based hydrogen storage materials. 2D nanostructured $\mathrm{Mg}$ films were synthesized through different techniques such as electron beam evaporation, direct current (DC) and radio frequency (RF) magnetron sputtering deposition, and plasma sputter and pulsed laser deposition. Jain et al. summarized the advantages of pure $\mathrm{Mg}$ films and $\mathrm{Mg}$ multilayered films. Thin films offer an alternative approach for producing nano-structured materials with better control over morphology, stoichiometry and contamination. ${ }^{23}$ Herein, we further review the role of nanofilms on the thermodynamic destabilization of $\mathrm{MgH}_{2}$ with more new evidence.

Thermodynamic destabilization of $\mathrm{MgH}_{2}$ via mechanical methods was first reported by Fujii. ${ }^{61}$ As shown in Fig. 16(a), the contraction of $\mathrm{PdH}_{x}$ layers to $\mathrm{Pd}$ upon heating induced a large compressive stress in the lattice of $\mathrm{MgH}_{2}$. The intrinsic stress is well correlated to grain size, where an increase in grain size accommodates a reduction in stress. In the $\mathrm{Pd} / \mathrm{Mg} / \mathrm{Pd}$ layered films fabricated by sputtering, the Mg layer was composed of fine columnar structures along the $c$-axis with a diameter in the 

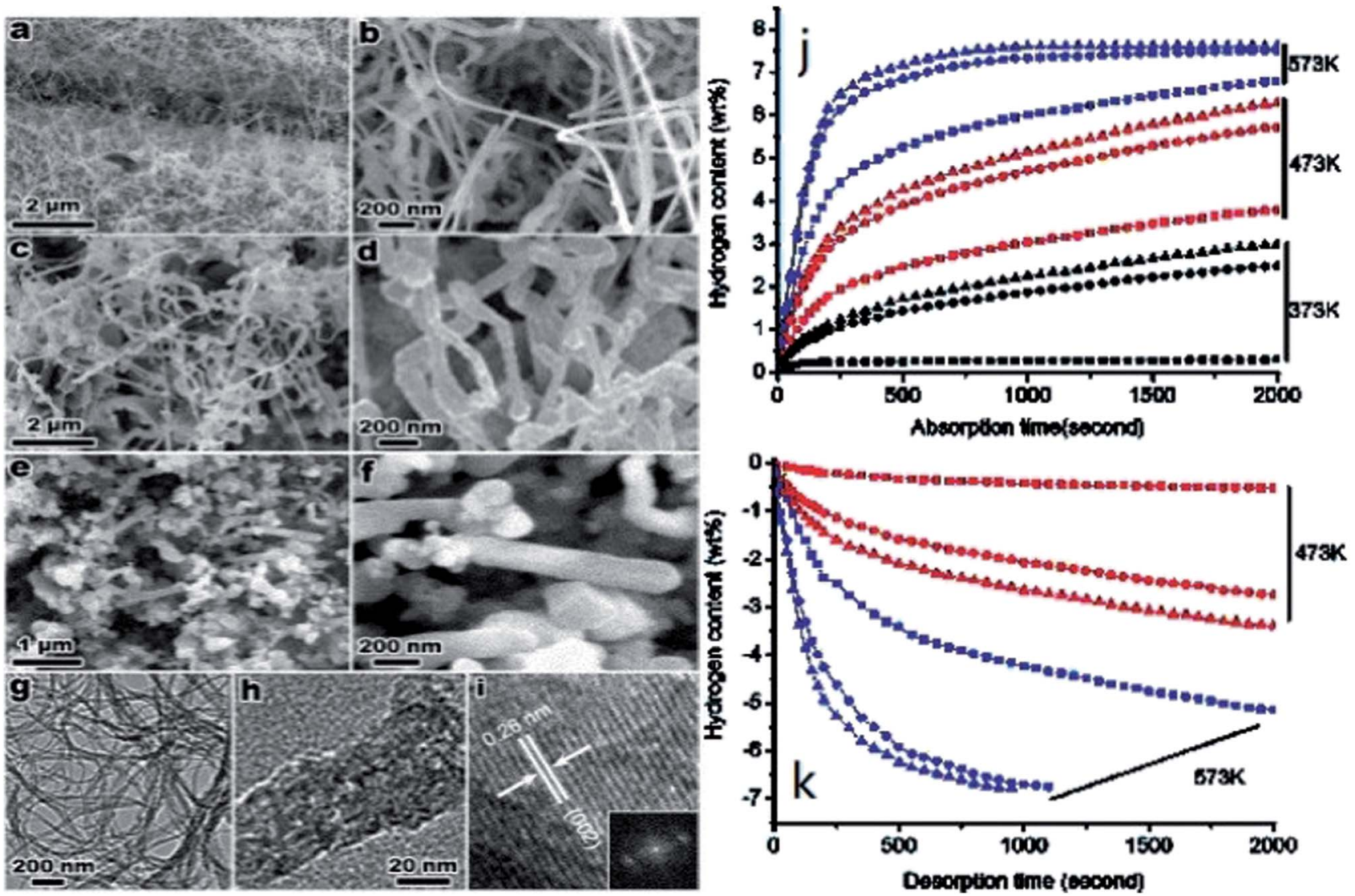

Fig. 14 Scanning electron microscopy (SEM) images of the Mg nanowires: (a and b) 30-50 nm, (c and d) 80-100 nm, and (e and f) 150-170 nm. TEM ( $g$ and h), and HRTEM (i) images of ( $a$ and b) with the corresponding fast Fourier transform (FFT) pattern (inset). Hydrogen absorption (j) and desorption ( $\mathrm{k}$ ) of the $\mathrm{Mg}$ nanowires (sample 1, triangles; sample 2, circles; and sample 3, squares) at different temperatures. ${ }^{59}$

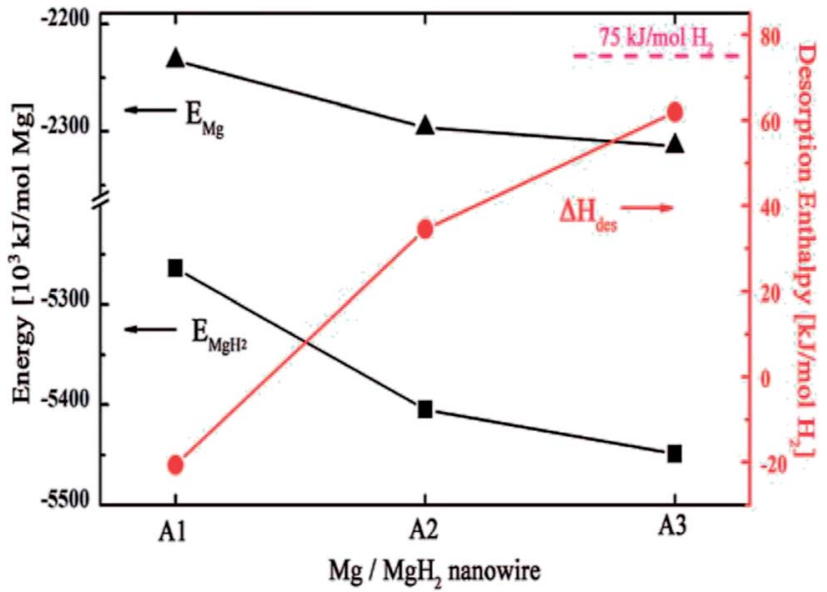

Fig. 15 Desorption enthalpy for $\mathrm{MgH}_{2}$ nanowires (red line) and the size effect of the calculated energies for magnesium (triangle) and $\mathrm{MgH}_{2}$ (tetragon) nanowires. ${ }^{60}$

range of 10-30 nm (Fig. 16(b)). This produced a large thermodynamic shift in the stability of $\mathrm{MgH}_{2}$ and reduced its sorption temperature to just above room temperature (measured in vacuum), which can be attributed to the cooperative phenomenon due to the elastic interaction between the nanostructured $\mathrm{Mg}$ and Pd layers. ${ }^{62}$

Subsequently, the hydrogen storage characteristics of multilayer $\mathrm{Mg}$ nanofilms have been investigated intensively. $\mathrm{MmM}_{5} /$

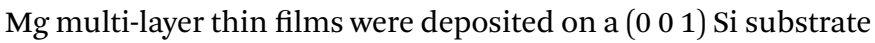
by direct current magnetron sputtering with a dual-target, and an advanced study proved that the apparent absorption of hydrogen in the $\mathrm{Mg}$ layer occurs at temperatures higher than $473 \mathrm{~K}$ and that the hydrogen absorbed can be fully released at $523 \mathrm{~K}^{63}$ Nanostructured $\mathrm{Mg}$ thin films grow in the shape of closely-stacked columns extending throughout the film thickness, while containing polycrystalline grains and grain boundary defects, which is responsible for the significant reduction in sorption temperature from 670 to $475 \mathrm{~K}$ by capping the $\mathrm{Mg}$ films with a thin Pd layer. ${ }^{64}$ Other studies proved that thermodynamic properties and cycle stability of $\mathrm{Mg}-\mathrm{Al}-\mathrm{Ti}$ thin films or $\mathrm{Mg}-\mathrm{Cr}-\mathrm{V}$ films are significantly improved compared with pure $\mathrm{MgH}_{2}{ }^{65,66}$

Baldi et al. ${ }^{67}$ revealed that the absorption plateau pressure can be altered when very thin layers of $\mathrm{Mg}$ are capped with a miscible element (Fig. 17). They assumed that the origins of this effect is due to 'elastic constraints', in accord with Fujii et al., meaning that the volume change in $\mathrm{MgH}_{2}$ is effectively restricted due to the small layer of alloying at the interface. The fundamental reasoning for this effect is the repulsive attraction 


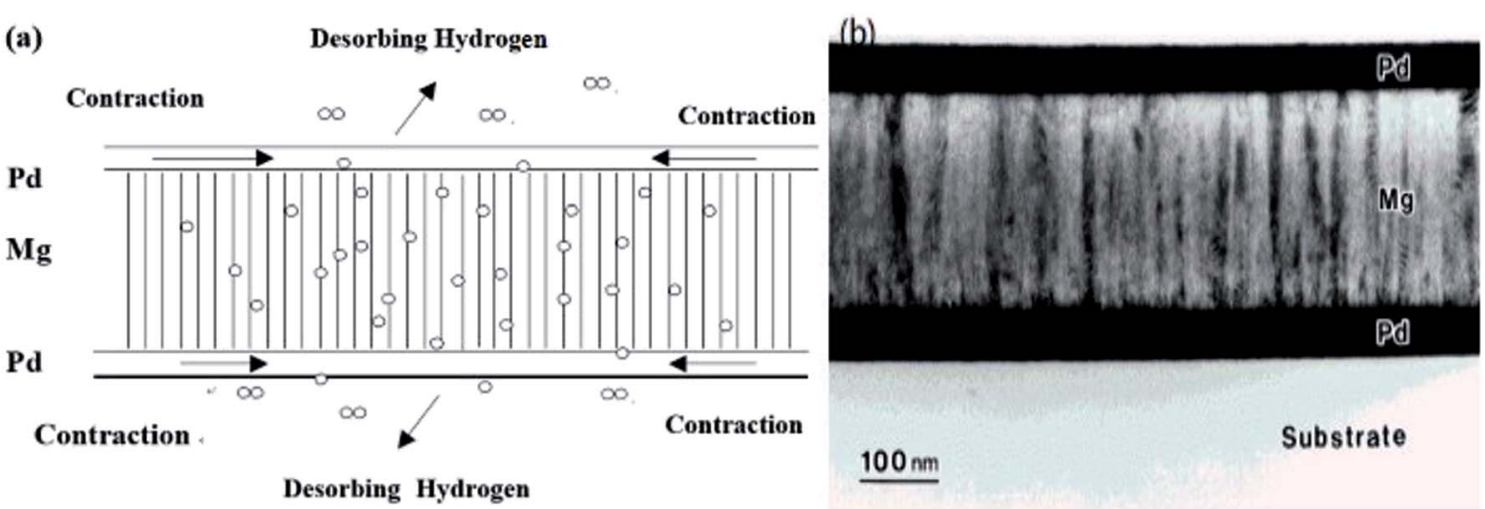

Fig. 16 Schematic representation of the co-operative phenomenon (a) and TEM micrographs of the cross-section of Pd (50 nm)/Mg (200 nm)/ Pd $(50 \mathrm{~nm})$ films before hydrogenation (b). ${ }^{61,62}$

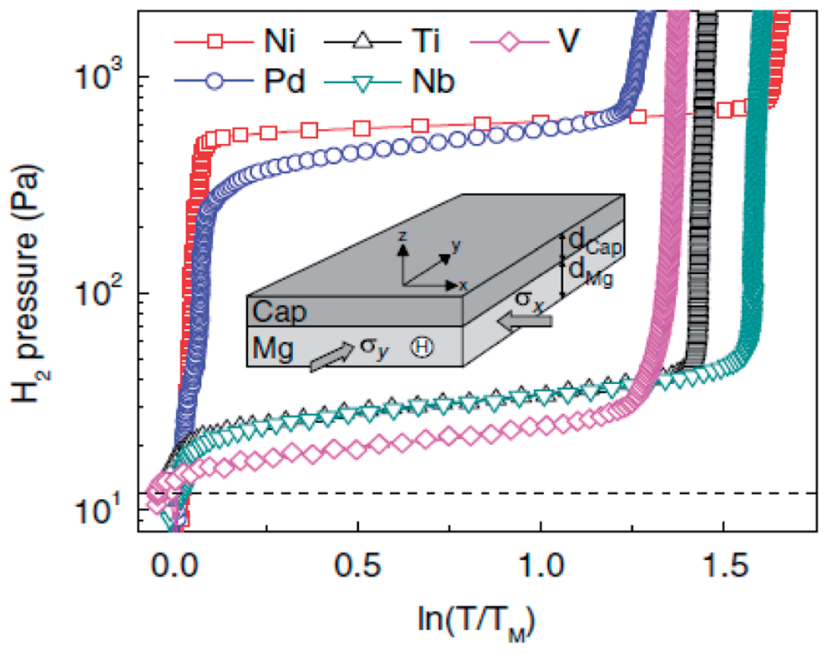

Fig. 17 Effect of cap layer: PTI measured at $333 \mathrm{~K}$ for $\mathrm{Ti}(10 \mathrm{~nm}) \mathrm{Mg}(20$ $\mathrm{nm}) \mathrm{X}(10 \mathrm{~nm}) \mathrm{Pd}(10 \mathrm{~nm})$ samples deposited on glass with $\mathrm{X}=\mathrm{Ni}, \mathrm{Pd}, \mathrm{Ti}$, $\mathrm{Nb}$, and $\mathrm{V} .{ }^{67}$

between the $\mathrm{H}-\mathrm{H}$ atoms within metals when volume expansion is restricted. Chung et al. ${ }^{\mathbf{6 8}}$ argued that the observed destabilization has a chemical origin, whereby the interfacial mixing of the $\mathrm{Mg} / \mathrm{Pd}$ regions requires additional energy for the formation of $\mathrm{MgH}_{2}$, which is exacerbated within thinner layers. In addition, Mooij et al. revealed that at very small thicknesses, the interface energies from adjacent layers become more important by synthesizing a wedge shaped $\mathrm{Mg}$ film with a thickness varying between 1-10 nm. ${ }^{69}$ Hughes et al. ${ }^{70}$ provided new insight into the destabilization mechanism by investigating the influence and comparative differences of Ti- and Y-based multilayers. It was remarkable that the Ti multilayers showed some destabilization with thinner layers down to $10 \mathrm{~nm}$, which is proposed to be due to interfacial energy contributions. In comparison, $\mathrm{Mg} / \mathrm{Y}$-based multilayers can provide a new route towards $\mathrm{MgH}_{2}$ destabilization due to the accommodation of lattice mismatch between the strained FCC Y/Mg interfaces.
4.2.4 Nanoconfinement. Nanoconfinement is an efficient route to hinder the particle growth and agglomeration of hydride particles within the supporting material and significantly improve the cycling property affected by the direct synthesis of nanostructured hydrides. A high-surface-area, nano-porous support for the active phase can facilitate the preparation of small particles and stabilize the particle size during heat treatments or cycling. In general, for hydrogen storage materials, the specific requirements for the matrix include light-weight, high loading of the active materials, not reactive towards the active materials, low-cost and abundant, such as carbon-based materials, organic polymers and ordered mesoporous oxides.

Recently, magnesium nanoparticles confined in carbon aerogels (CA) have attracted much attention. ${ }^{71-73}$ Liu et al. ${ }^{72}$ reported magnesium nanoparticles confined in carbon aerogels through the hydrogenation of infiltrated dibutyl-magnesium followed by hydrogen desorption at $623 \mathrm{~K}$, which has a size in the range of 5.0 to $20.0 \mathrm{~nm}$. The hydrogenation and dehydrogenation enthalpies of the confined $\mathrm{Mg}$ were determined to be $65.1 \pm 1.56 \mathrm{~kJ}\left(\mathrm{~mol}^{-1} \mathrm{H}_{2}\right)$ and $68.8 \pm 1.03 \mathrm{~kJ}\left(\mathrm{~mol}^{-1} \mathrm{H}_{2}\right)$, respectively. Jia et $a .^{74}$ prepared the $\mathrm{MgH}_{2} @ \mathrm{CMK}-3$ nanoconfinement system and experimentally realized low temperature hydrogen release starting from $323 \mathrm{~K}$. Comparing the calculated reaction energy $\left(E_{\mathrm{r}}\right)$ of clusters of pure $\mathrm{MgH}_{2}$ and $\mathrm{MgH}_{2} / \mathrm{C}$ (Fig. 18), they concluded that the interfacial effect can effectively improve the low-temperature release properties of $\mathrm{MgH}_{2}$ clusters, even if the cluster is not ultra-small (Fig. 18c). Consequently, they proposed a new mechanism for destabilizing $\mathrm{Mg}-\mathrm{H}$ bonding via the combination of the size effect and $\mathrm{MgH}_{2}$-carbon scaffold interfacial bonding, which is more superior than nanoparticles or 2D films.

Modifying the surface of NPs with a gas-selective outer layer of polymer or elemental metal has been well demonstrated to be a feasible route to obtain superior gas-selective permeability and structural stability. Jeon et al. ${ }^{75}$ reported the synthesis of an air-stable composite material consisting of metallic $\mathrm{Mg}$ nanocrystals (NCs) in a gas-barrier polymer matrix, which enabled them to absorb and release hydrogen without oxidation 


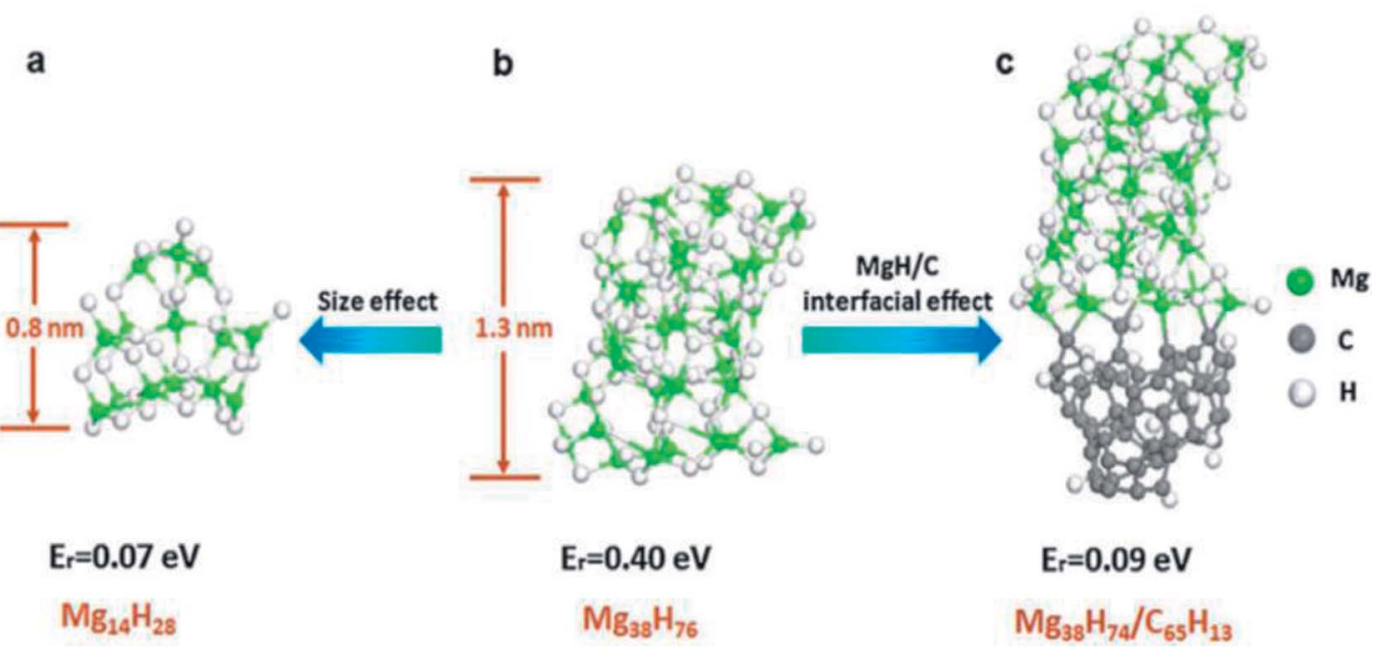

Fig. 18 Reaction energy $\left(E_{r}\right)$ for hydrogen release from clusters of pure $\mathrm{MgH}_{2}$ and $\mathrm{MgH}_{2} / \mathrm{C}$. (a) $\mathrm{Mg}_{14} \mathrm{H}_{28}$ Cluster, (b) $\mathrm{Mg}_{38} \mathrm{H}_{76} \mathrm{Cluster}$ and (c) $\mathrm{Mg}_{38} \mathrm{H}_{74}$ adsorbed on a cluster of amorphous carbon. ${ }^{74}$

(Fig. 19(a)). The average Mg NCs diameter was 4.9-2.1 nm (Fig. 19(b)) and the composite material enabled both the storage of a high density of hydrogen (up to $6 \mathrm{wt} \%$ of $\mathrm{Mg}$ and $4 \mathrm{wt} \%$ for the composite) and rapid kinetics (loading in $<30 \mathrm{~min}$ at $473 \mathrm{~K}$ ) (Fig. 19(c)). Moreover, nanostructuring of $\mathrm{Mg}$ results in rapid storage kinetics without using expensive heavy metal catalysts. Besides, graphene nanosheets and gas-selective reduced graphene oxide ( $\mathrm{rGO}$ ) have received much attention due to their high hydrogen selectivity. ${ }^{76,77}$ Cho et al. ${ }^{78}$ reported the development of similar materials, which were comprised of nickeldoped $\mathrm{Mg}$ nanocrystals encapsulated by molecular-sieving reduced graphene oxide (rGO) layers, with simultaneously high hydrogen storage capacity $(6.5 \mathrm{wt} \%$ for the total composite) and excellent kinetics, while maintaining robustness. Overall, this approach of synthesizing nanosized airsensitive metal nanocrystals protected in a gas-selective polymer provides new opportunities for low-cost high-capacity hydrogen storage media, batteries and fuel cells.

Remarkably, Cui et al. ${ }^{79}$ provided another way to successfully load $\mathrm{Mg}$ into the nano-sized pores of an anodic aluminum oxide (AAO) template for realizing the nano-confinement of $\mathrm{Mg}$ via vapor transport deposition with a slight reduction in the hydrogen desorption enthalpy of $\mathrm{MgH}_{2}$ from $(74.42 \pm 0.12)$ to $(73.21 \pm 0.04) \mathrm{kJ}\left(\mathrm{mol}^{-1} \mathrm{H}_{2}\right)$. There was more evidence for the reduction in desorption temperature when $\mathrm{MgH}_{2}$ was embedded within an LiCl salt matrix. ${ }^{80}$ The particle size of $7 \mathrm{~nm}$ showed a reduction in desorption temperature of $6 \mathrm{~K}$. Although this is smaller than expected, it shows the possibility of destabilization.

Over the past few decades, the thermodynamic destabilization mechanisms of nanostructured materials for hydrogen storage applications have been well demonstrated, including size effects, lattice strain, interface energies, elastic constraints, and combination of the size effect and interface energies. Remarkable advances have been achieved in destabilizing thermodynamics by taking advantage of the above mechanisms. However, there is an urgent need to address the agglomeration of particles in support-free nano-scaled hydrides or nanowires since it results in collapse of the nanostructure after repeated hydrogen uptake and release cycles, which is still a significant challenge. It is generally accepted that nanoconfinement leads to an obvious loss in the gravimetric
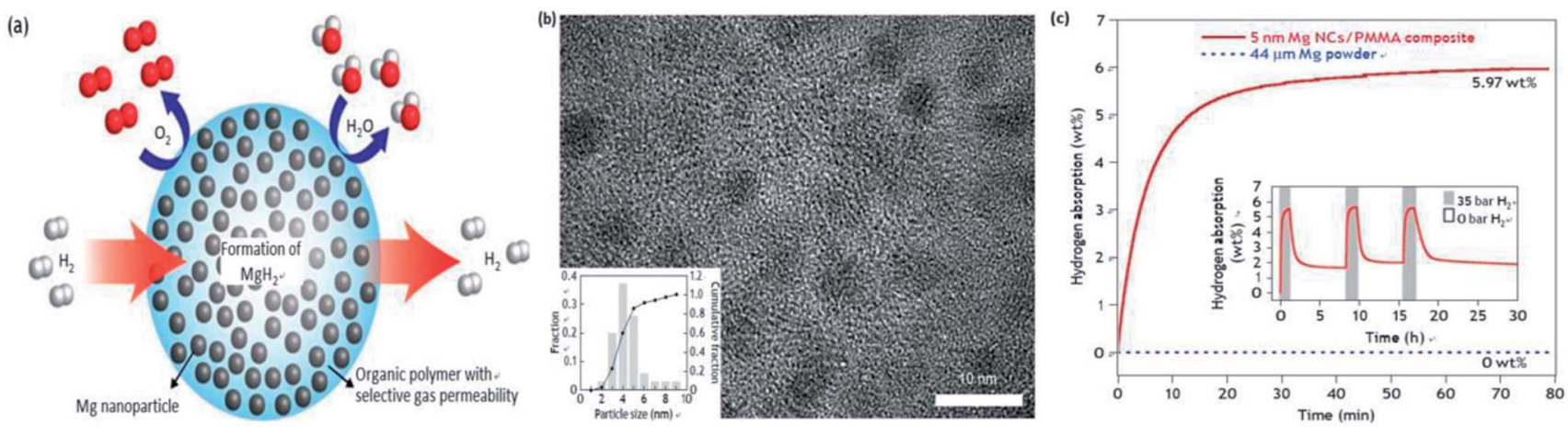

Fig. 19 (a) Schematic of hydrogen storage composite material: high-capacity Mg NCs are encapsulated by a selectively gas-permeable polymer, (b) HRTEM of the nanocomposite and particle size distribution of $\mathrm{Mg}$ in the polymer matrix, and (c) hydrogen absorption kinetic analyses of bulk $\mathrm{Mg}$ and Mg/PMMA composites at $473 \mathrm{~K}$ and 35 bar hydrogen. ${ }^{75}$ 
hydrogen storage capacity compared with that of $\mathrm{MgH}_{2}$ and the low loading of Mg NPs is still a big problem. Besides, the synthesis of nanostructured materials is another challenge for practical applications.

\subsection{Metastable phases}

Many groups have reported the preparation methods, crystal structures, thermodynamic properties and hydrogen desorption paths of $\gamma-\mathrm{MgH}_{2}$. Generally, high-pressure phase $\gamma-\mathrm{MgH}_{2}$ can be obtained by heating $\alpha-\mathrm{MgH}_{2}$ (ref. 81) or $\mathrm{BM} \alpha-\mathrm{MgH}_{2}{ }^{82}$ The deuterium atoms surround magnesium in a distorted octahedral configuration with bond distances of Mg-D $=1.915(3)$, 1.943(3) and 2.004(3) $\AA^{82}$ The thermodynamic properties of $\gamma$ and $\beta-\mathrm{MgH}_{2}$ have also been determined by the first-principle calculations, where the supercell based on the $\gamma-\mathrm{MgH}_{2}\left(\begin{array}{lll}1 & 1 & 0\end{array}\right)$ plane is the most unstable with a surface energy of $1.23 \mathrm{~J} \mathrm{~m}^{-2}$ and dehydriding enthalpy change of $44.66 \mathrm{~kJ} \mathrm{~mol}^{-1}$, while that of the $\beta-\mathrm{MgH}_{2}\left(\begin{array}{lll}1 & 1 & 0\end{array}\right)$ plane has a surface energy of $0.19 \mathrm{~J} \mathrm{~m}^{-2}$ and enthalpy change of $78.16 \mathrm{~kJ} \mathrm{~mol}^{-1}$. This is because in $\gamma$ $\mathrm{MgH}_{2}$, the $\mathrm{H}$ octahedrons surrounding the $\mathrm{Mg}$ atoms are deformed and the octahedron chain takes a zigzag form instead of the straight chain in the $\beta$ phase. ${ }^{12}$ Thus, we can conclude that conversion to the metastable $\gamma-\mathrm{MgH}_{2}$ phase should lead to improved hydrogen sorption properties and provide another approach to modify the thermodynamics of $\mathrm{Mg}$-based materials. However, irreversible reconversion of the $\gamma$-phase into the $\beta$-phase ${ }^{83}$ or $\mathrm{Mg}^{84}$ occurs during heat treatment at $583 \mathrm{~K}$ in 1 bar hydrogen atmosphere.

Numerous researchers have shown that ball milling is an efficient way to obtain a high proportion of $\gamma-\mathrm{MgH}_{2}$. Zhou et al. ${ }^{12}$ prepared magnesium hydride via reactive milling under a hydrogen atmosphere using carbon as a milling aid. The enthalpy change determined by experimental isotherms gradually decreased with more $\gamma-\mathrm{MgH}_{2}$ from a longer milling time. They also found that the unstable $\gamma-\mathrm{MgH}_{2}$ in the as-milled material disappeared during desorption/absorption cycle. Xiao et $a l .{ }^{83}$ made use of a simple wet chemical route by ball milling $\mathrm{MgH}_{2}$ with $\mathrm{LiCl}$ as a PCA at room temperature followed by tetrahydrofuran (THF) treatment under an Ar atmosphere to obtain a magnesium hydride composite $\left(\mathrm{MgH}_{2}-\mathrm{E}\right)$, which was composed of $18 \mathrm{wt} \%$ orthorhombic $\gamma-\mathrm{MgH}_{2}$ with particle lengths/widths ranging from 50-400 nm. The $\beta-/ \gamma-\mathrm{MgH}_{2}$ nanocomposite exhibited a dehydrogenation capacity of $6.6 \mathrm{wt} \%$ and started to release hydrogen at $533 \mathrm{~K}$ (Fig. 20), which can be attributed to both the existence of the $\mathrm{MgH}_{2}$ nanostructure and the presence of $\gamma-\mathrm{MgH}_{2}$. However, they failed to determine the hydrogen desorption path of $\gamma-\mathrm{MgH}_{2}$ due to the limited available data and experimental methods.

Shen et $a{ }^{85}$ reported the electrochemical synthesis of nanosized $\mathrm{Mg}$, leading to the formation of a mixed $\gamma / \beta$ hydride phase upon hydrogen absorption with a high $\gamma-\mathrm{MgH}_{2}$ content (29.6\%) with a crystallite size of $10.9 \pm 0.7 \mathrm{~nm}$. High-resolution transmission electron microscopy (HRTEM) also locally confirmed the formation of $\gamma$ - and $\beta-\mathrm{MgH}_{2}$ (Fig. 21(b)), and this indicated that individual magnesium particles may contain both phases. As shown in Fig. 21(a), the decomposition of $\gamma$ -

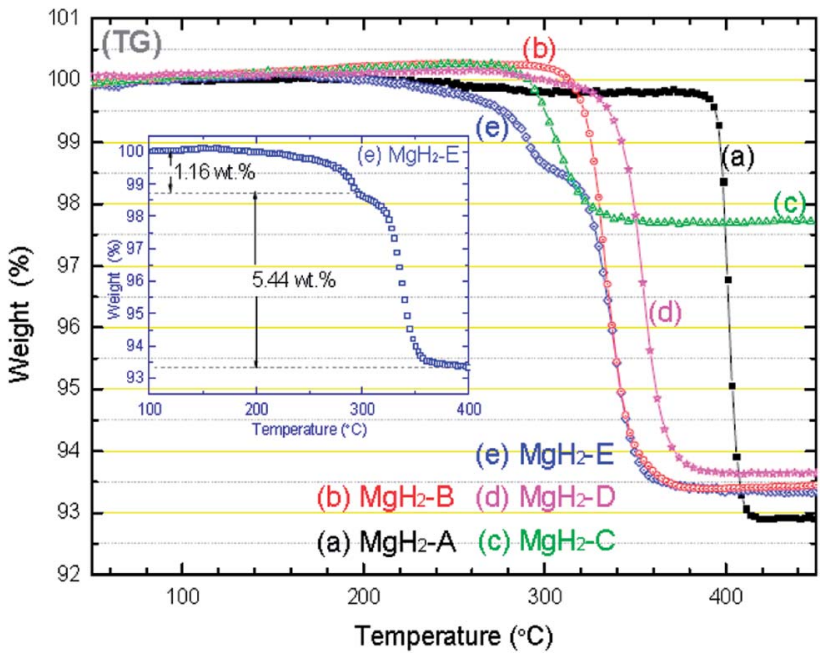

Fig. 20 TG-DTA curves of (a) MgH2-A, (b) MgH2-B, (c) $\mathrm{MgH}_{2}-\mathrm{C}$, (d) $\mathrm{MgH} 2-\mathrm{D}$, and (e) $\mathrm{MgH} 2-\mathrm{E}$ samples. The heating rate was $2{ }^{\circ} \mathrm{C} \mathrm{min}-1$ from room temperature to $450^{\circ} \mathrm{C}$ in each case. The inset shows the detail of the mass loss profile for $\mathrm{MgH} 2-\mathrm{E}^{83}$

$\mathrm{MgH}_{2}$ starts the same time as that of $\beta-\mathrm{MgH}_{2}$ with the simultaneous generation of hexagonal $\mathrm{Mg}$. Thus, it is evident that both phases are intrinsically linked and $\gamma-\mathrm{MgH}_{2}$ may trigger the decomposition of $\beta-\mathrm{MgH}_{2}$. The presence of $\gamma-\mathrm{MgH}_{2}$ was found to cause a significant reduction in the apparent activation energy from $106.2 \pm 4.0$ to $69.1 \pm 2.9 \mathrm{~kJ} \mathrm{~mol}^{-1}$ and a reduction

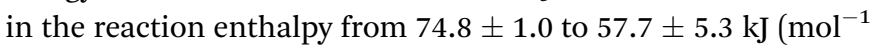
$\mathrm{H}_{2}$ ). It is notable that metastable $\gamma-\mathrm{MgH}_{2}$ has potential to lead to better kinetics and thermodynamic properties for the $\mathrm{Mg}$ / $\mathrm{MgH}_{2}$ system. This is consistent with the study conducted by Ponthieu, ${ }^{86}$ in which for Ti-containing nanocomposites, both $\gamma$ and $\beta-\mathrm{MgD}_{2}$ desorbed simultaneously above $475 \mathrm{~K}$ together with a concomitant increase in the $\mathrm{Mg}$ phase according to the reaction (7):

$$
x\left(\gamma-\mathrm{MgH}_{2}\right)+(1-x)\left(\beta-\mathrm{MgH}_{2}\right) \rightarrow \mathrm{Mg}+\mathrm{H}_{2}
$$

The results show that the presence of $\gamma-\mathrm{MgH}_{2}$ destabilizes the $\beta-\mathrm{MgH}_{2}$ phase and shows a synergetic effect during hydrogen desorption, reducing the $\beta-\mathrm{MgH}_{2}$ desorption temperature. ${ }^{87}$

Considering the achieved progress, although $\gamma-\mathrm{MgH}_{2}$ can be synthesized by heating the low-pressure phase, ball milling or hydrogenation of nanosized $\mathrm{Mg}$ and alter the thermodynamic properties of $\mathrm{Mg} / \mathrm{MgH}_{2}$ without loss in its hydrogen storage capacity, the problems of bad cycle performance under high temperature and low proportion of $\gamma-\mathrm{MgH}_{2}$ still need to be addressed in further studies. However, it is promising that $\gamma$ $\mathrm{MgH}_{2}$ can exist stably with a decrease in desorption temperature and increase of proportion of $\gamma-\mathrm{MgH}_{2}$. Besides, Song et al. ${ }^{\mathbf{8}}$ predicted a metastable phase of $\mathrm{MgH}_{2}$ by first principle calculations, where the metastable phase has a tetragonal symmetry (I4/ /amd, group 141) and meets all the mechanical stability criteria, and its formation enthalpy is $-58.03 \mathrm{~kJ} \mathrm{~mol}^{-1} \mathrm{H}_{2}$. 
(a)

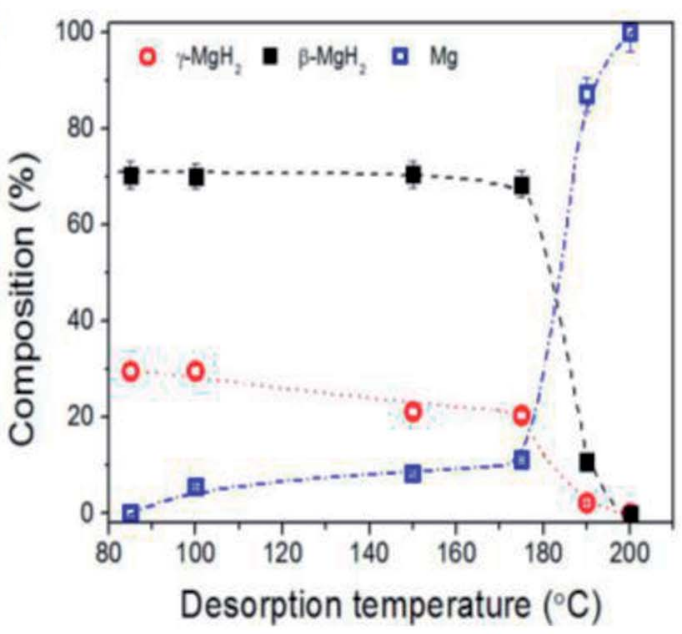

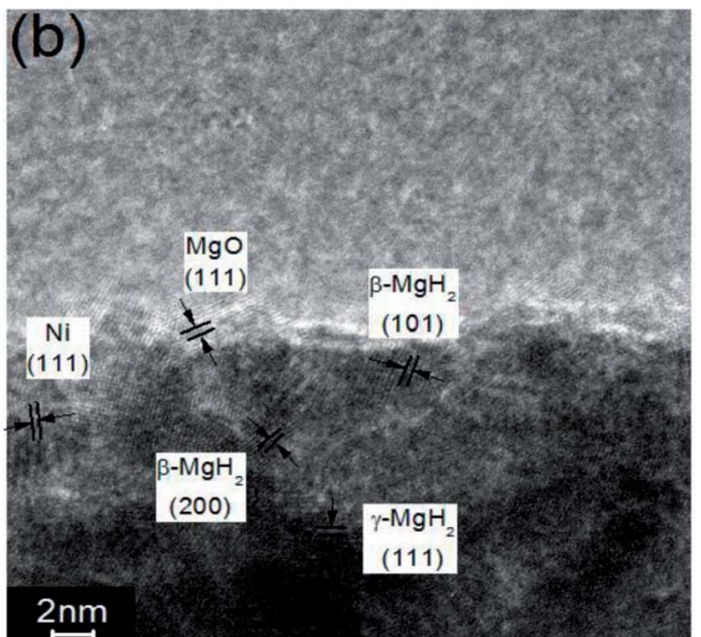

Fig. 21 Thermal stability of $\gamma-\mathrm{MgH}_{2}$ during hydrogen desorption as function of desorption temperature (a) and HRTEM images of electrosynthesized $\mathrm{Mg}$ after hydrogen absorption at $100{ }^{\circ} \mathrm{C}$ (b)..$^{85}$

Hence, the tetragonal structure is more desirable than $\alpha-\mathrm{MgH}_{2}$ for practical hydrogen storage applications. However, this needs to be further confirmed by experimental data.

\subsection{Changing reaction pathway}

Fig. 22 shows a general enthalpy diagram illustrating the destabilization of a strongly bound hydride through the addition of a reactive additive.$^{89}$ The alloying additive, $\mathrm{B}$, reduces the dehydrogenation enthalpy through the formation of $\mathrm{AB}_{x}$ and effectively destabilizes the hydride, $\mathrm{AH}_{2}$. This reaction occurs with a reduced enthalpy and therefore, increases the equilibrium pressure and decreases the dehydrogenation temperature.

An intensively system investigated is the $\mathrm{MgH}_{2}-\mathrm{Si}$ system, in which, $\mathrm{Mg}_{2} \mathrm{Si}$ forms upon dehydrogenation according to reaction (8):

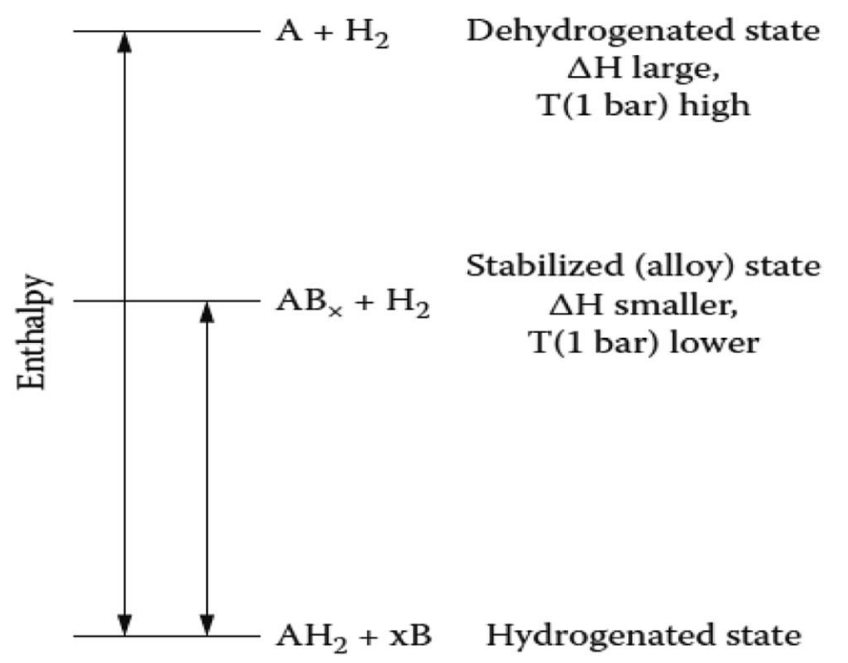

Fig. 22 Generalized enthalpy diagram illustrating destabilization through alloy formation upon dehydrogenation. ${ }^{89}$

$$
2 \mathrm{MgH}_{2}+\mathrm{Si} \rightarrow \mathrm{Mg}_{2} \mathrm{Si}+2 \mathrm{H}_{2}
$$

Thermodynamic calculations indicate the 1 bar equilibrium pressure is at approximately $293 \mathrm{~K}$ and 100 bars at approximately $423 \mathrm{~K}$. Thus, it is concluded that the $\mathrm{MgH}_{2} / \mathrm{Si}$ system, with a hydrogen capacity of $5.0 \mathrm{wt} \%$, is practical for hydrogen storage at reduced temperatures. Hence, alloying Si with $\mathrm{MgH}_{2}$ is supposed to significantly destabilize the $\mathrm{Mg}-\mathrm{H}$ bond with the enthalpy reduced to $41 \mathrm{~kJ}\left(\mathrm{~mol}^{-1} \mathrm{H}_{2}\right)$ due to the formation of $\mathrm{Mg}_{2} \mathrm{Si}$ in eqn (8). ${ }^{90}$ However, the re-hydrogenation of $\mathrm{Mg}_{2} \mathrm{Si}$ was found to be severely limited by the reaction kinetics and the mass transport of $\mathrm{Mg}$ and $\mathrm{Si}$ into separate phases. ${ }^{\mathbf{9 1 , 9 2}}$ Gennari et $a l .{ }^{93}$ found that the presence of Ge decreases the hydride decomposition temperature in the range of 323 to $423 \mathrm{~K}$, which was prepared by mechanical milling. Meanwhile, Walker et al. ${ }^{94}$ started with $\mathrm{MgH}_{2}$ and milled it with Ge under an Ar atmosphere to prepare $\mathrm{Mg}_{2} \mathrm{Ge}$ (eqn (9)).

$$
2 \mathrm{MgH}_{2}+\mathrm{Ge} \rightarrow \mathrm{Mg}_{2} \mathrm{Ge}+2 \mathrm{H}_{2}
$$

Their results showed that Ge acts as a thermodynamic destabilization agent for $\mathrm{MgH}_{2}$, resulting in a dramatic decrease in the $\Delta H$ of dehydrogenation to $14 \mathrm{~kJ}\left(\mathrm{~mol}^{-1} \mathrm{H}_{2}\right)$. This dramatically reduced the temperature of dehydrogenation to $403 \mathrm{~K}$, but unfortunately, the desorption product $\mathrm{Mg}_{2} \mathrm{Ge}$ could not absorb hydrogen to form $\mathrm{MgH}_{2}$ and Ge. In addition, the additives Si and Ge cannot form hydrides; thus, the hydrogen capacity was partially lost.

Aluminum also forms stable compounds or alloys with $\mathrm{Mg}$, such as $\mathrm{Mg}_{17} \mathrm{Al}_{12}$ ( $\gamma$ phase) and $\mathrm{Mg}_{2} \mathrm{Al}_{3}$ (eqn (10)).

$$
\begin{aligned}
17 \mathrm{MgH}_{2}+12 \mathrm{Al} \leftrightarrow & 9 \mathrm{MgH}_{2}+4 \mathrm{Mg}_{2} \mathrm{Al}_{3}+8 \mathrm{H}_{2} \leftrightarrow \mathrm{Mg}_{17} \mathrm{Al}_{12} \\
& +17 \mathrm{H}_{2}
\end{aligned}
$$

However, the destabilization effect of this systems is rather small (only about $50 \mathrm{~K}$ decrease in decomposition start temperature), and the theoretical hydrogen content of $\mathrm{MgH}_{2}-\mathrm{Al}$ 
can reach 4.4 wt\% with a small decrease in the desorption enthalpy $\Delta H$ of $6 \mathrm{~kJ}\left(\mathrm{~mol}^{-1} \mathrm{H}_{2}\right) \cdot{ }^{95}$ The reversible hydrogenation was accomplished in three transformation steps (Fig. 23), where initially, only $\mathrm{Mg}$ reacts and forms $\mathrm{MgH}_{2}$, then the $\gamma-\mathrm{Mg}_{17} \mathrm{Al}_{12}$ phase is decomposed into the $\mathrm{Mg}$-poor $\beta-\mathrm{Mg}_{2} \mathrm{Al}_{3}$ phase. Finally, the $\mathrm{Mg}$-hydride phase is fully formed from the resulting $\mathrm{Mg}_{2} \mathrm{Al}_{3} \cdot{ }^{96}$

Significant progress has been achieved to alter the hydrogen storage properties of $\mathrm{Mg}$-based materials, where their $\Delta H$ undergoes a great decrease through alloying, nanostructuring, forming metastable phases and changing the reaction path, as shown in Table 4. However, none of these strategies totally satisfy the requirements of practical applications; thus, so further studies on the thermodynamic properties of $\mathrm{Mg} / \mathrm{MgH}_{2}$ need to be performed to realize the practical application goals by DOE (Table 1). The future looks bright for the combination of alloying, nanostructuring, and metastable phase.

\section{Novel Mg-based composite materials}

Altering the thermodynamic properties of $\mathrm{Mg} / \mathrm{MgH}_{2}$ via a single measure cannot satisfy the requirements for its practical application. Therefore, the introduction of appropriate metal hydrides/dopants was proposed to further modify its thermodynamic properties. The widely studied Mg-based composites include $\mathrm{Mg}-\mathrm{Ni}-\mathrm{RE},{ }^{97-99} \mathrm{Mg}-\mathrm{Ni}-\mathrm{Ti},{ }^{100} \mathrm{MgH}_{2}-\mathrm{LiBH}_{4}{ }^{101} \mathrm{LiNH}_{2}-$ $\mathrm{MgH}_{2},{ }^{102} \mathrm{LiBH}_{4}-\mathrm{Mg}_{2} \mathrm{NiH}_{4},{ }^{103}$ and $\mathrm{MgH}_{2}-\mathrm{NaAlH}_{4} \cdot{ }^{104}$

\subsection{Amorphization}

Amorphization as a novel method can alter the hydrogen storage properties of $\mathrm{Mg}$-based materials with more specific octahedral and/or tetrahedral sites for hydrogen occupation and extra potential vacancies for hydrogenation. Mg-RE-Ni

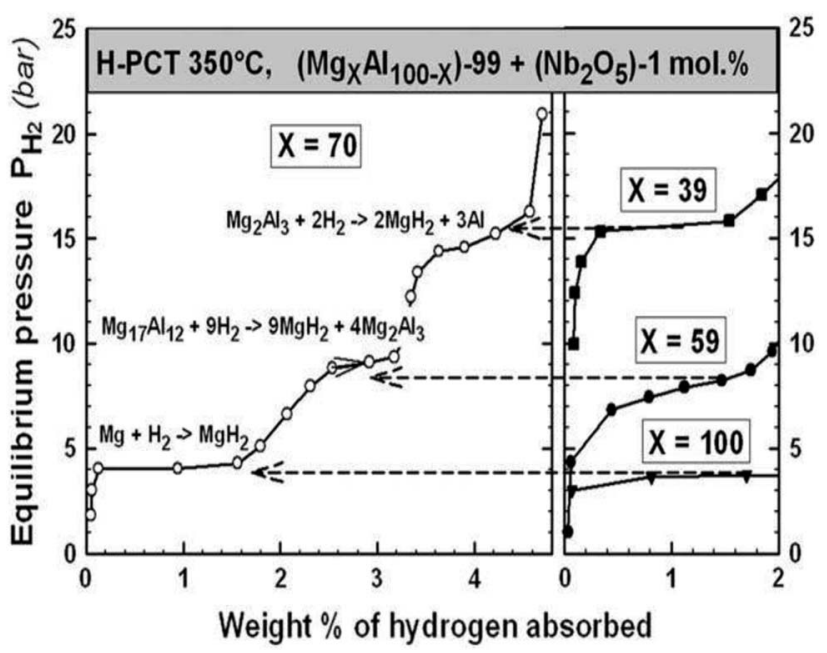

Fig. 23 Summary of the PCT absorption curves of the $\left(\mathrm{Mg}_{x} \mathrm{Al}_{100-X}\right)-$ $99+\left(\mathrm{Nb}_{2} \mathrm{O}_{5}\right)-1$ mol\% samples. The 3 steps of transformation from the $X=70$ samples are compared to the absorption curves of the $X=$ $100(\mathrm{Mg}), X=59\left(\mathrm{Mg}_{17} \mathrm{Al}_{12}\right)$ and $X=39\left(\mathrm{Mg}_{2} \mathrm{Al}_{3}\right)$ compounds. ${ }^{96}$ amorphous alloys prepared by melt-spinning are typical examples with a hydrogen density as high as $5.5 \mathrm{wt} \%$ at $573 \mathrm{~K}$, and the microstructure of the as-spun alloys consist of an amorphous matrix containing $\mathrm{MgH}_{2}, \mathrm{Mg}_{2} \mathrm{NiH}_{4}$ and $\mathrm{REH}_{x}{ }^{97}$ Lin et $a .^{98}$ found that the $\mathrm{Mg}-\mathrm{Ce}-\mathrm{Ni}$ metallic glasses (MGs) can reversibly absorb and desorb about $0.2-0.4 \mathrm{wt} \% \mathrm{H}$ at room temperature without activation, and the hydrogenation capacity of the glassy Mg-based alloy is twice that of the corresponding crystalline alloy due to its free volume and disordered atomic structure.

Recent studies showed that desirable properties can realized by combining crystalline and amorphous materials, which are better than that of the amorphous counterpart. Due to the combination of nanocrystalline magnesium matrix and the amorphous nickel inter-grain region, $\mathrm{Mg}-\mathrm{Ni}$ nano/amorphous composite materials are superior over their amorphous counterpart in hydrogen storage capacity and kinetics. ${ }^{99}$ Besides, it was also found that $\mathrm{Mg}-\mathrm{Ni}-\mathrm{La}$ nano/amorphous composite materials with the starting temperature of hydrogen desorption from $473 \mathrm{~K}$ to $298 \mathrm{~K}$ have better properties than their $\mathrm{Mg} 50 \%-$ Ni 50\% composite material. This indicates that the thermodynamic stability of $\mathrm{Mg}-\mathrm{Ni}$ nano/amorphous composite materials can be reduced by additives such as La. ${ }^{99}$ Another research reported that the nanostructured $50 \% \quad \mathrm{Mg}_{1.5} \mathrm{Mn}_{0.5} \mathrm{Ni} / 50 \%$ $\mathrm{LaNi}_{3.75} \mathrm{Mn}_{0.75} \mathrm{Al}_{0.25} \mathrm{Co}_{0.25}$ composite material can release $\mathrm{H}_{2}$ at room temperature as a result of the combined engineering of many factors, including alloying, surface properties, microstructure, grain size and others. ${ }^{105}$

\subsection{Novel reactant mixtures}

The U.S. Department of Energy Metal Hydride Center of Excellence (MHCoE) conducted substantial research into new reversible hydrogen storage materials for light-duty vehicles, which is composed of three main fields: mechanisms and modeling, materials development, and system design and materials engineering. ${ }^{\mathbf{1 0 6}}$ Alapati et al. ${ }^{\mathbf{1 0 2}}$ theoretically predicted the $\mathrm{LiNH}_{2}+\mathrm{MgH}_{2}(1: 1)$ system due to its very attractive theoretical desorption enthalpy of $\Delta H=32 \mathrm{~kJ}\left(\mathrm{~mol}^{-1} \mathrm{H}_{2}\right)$, with a hydrogen capacity of $8.2 \mathrm{wt} \%$ by the following reaction:

$$
\mathrm{MgH}_{2}+\mathrm{LiNH}_{2} \rightarrow \mathrm{LiMgN}+2 \mathrm{H}_{2}
$$

The high predicted weight percentage of hydrogen is due to its full dehydrogenation to LiMgN, bypassing the undesirable imide intermediate, as shown in Fig. 24. Based on this, substantial work has been done to demonstrate the feasibility of reaction (11) experimentally. ${ }^{107-109}$ The total weight loss was $8.1 \mathrm{wt} \%$ of the initial weight after the sample was held at $493 \mathrm{~K}$ for $20 \mathrm{~min}$, with a $\Delta H$ of $33.5 \mathrm{~kJ} \mathrm{~mol}^{-1} \mathrm{H}_{2}$, which is very close to the theoretically predicted reaction enthalpy. ${ }^{\mathbf{1 1 0}}$ However, its application has been greatly hindered by its rather high activation energy barriers.

Based on these results, Dolotko et al. ${ }^{111}$ demonstrated thermochemical transformations in $2 \mathrm{MNH}_{2}-3 \mathrm{MgH}_{2}$ systems $(\mathrm{M}=$ $\mathrm{Li}$ or $\mathrm{Na}$ ). A total of $6.45 \mathrm{wt} \%$ of hydrogen was released by the $2 \mathrm{LiNH}_{2}-3 \mathrm{MgH}_{2}$ system beginning at $459 \mathrm{~K}$, and a total of 
Table $4 \Delta H$ and hydrogen storage capacity of $\mathrm{Mg}$-based hydrogen materials

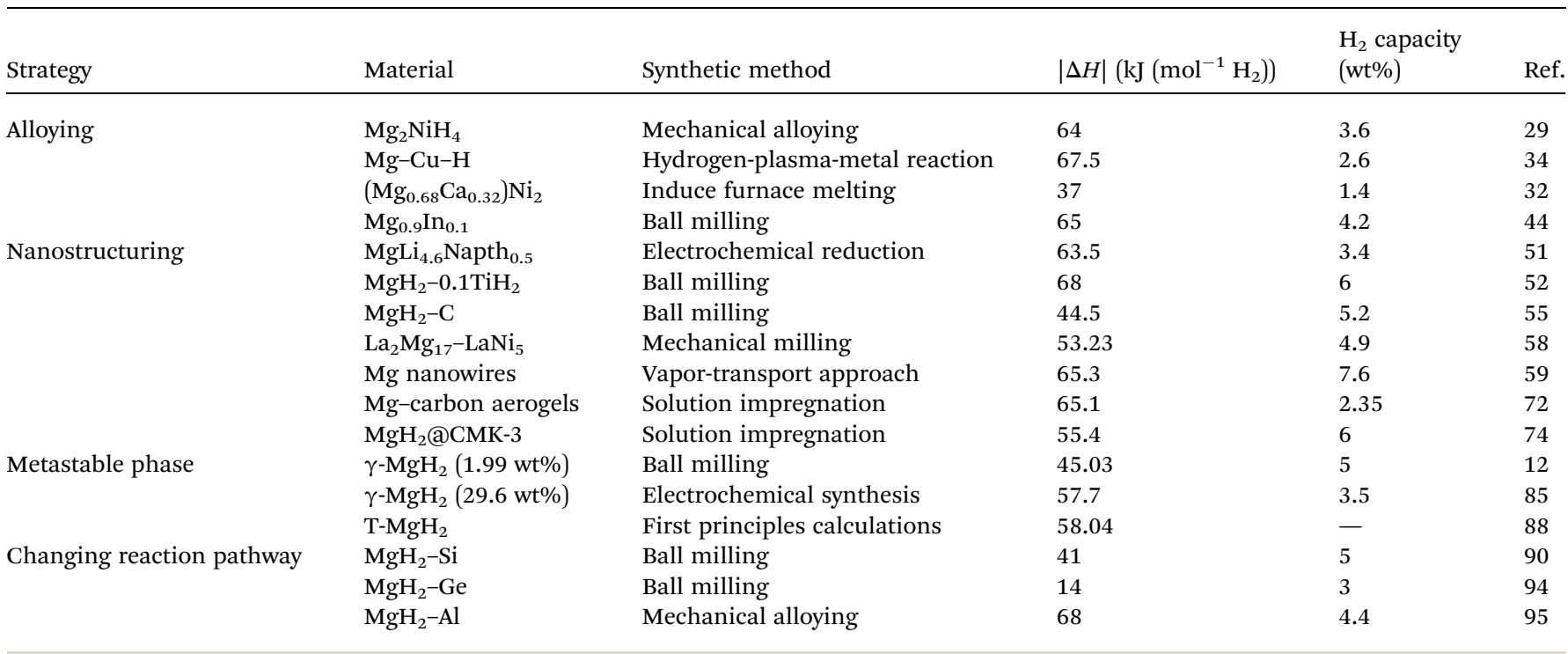

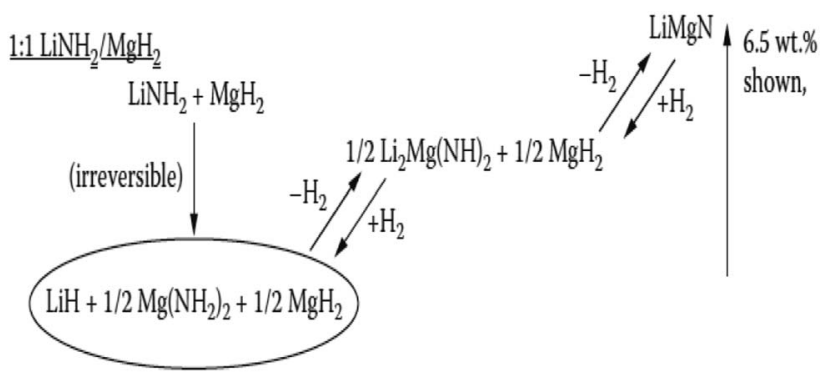

Fig. 24 Mechanism for hydrogen absorption/desorption of $1: 1$ $\mathrm{LiNH}_{2} / \mathrm{MgH}_{2}{ }^{102}$

$5.1 \mathrm{wt} \% \mathrm{H}_{2}$ was released by the $2 \mathrm{NaNH}_{2}-3 \mathrm{MgH}_{2}$ system starting at $403 \mathrm{~K}$ according to the following solid state transformation:

$$
2 \mathrm{MNH}_{2}+3 \mathrm{MgH}_{2} \rightarrow \mathrm{Mg}_{3} \mathrm{~N}_{2}+2 \mathrm{MH}+4 \mathrm{H}_{2} \uparrow
$$

Other groups further studied $\mathrm{LiNH}_{2}-n \mathrm{MgH}_{2}(n=0.5,0.7,0.9$, 1.0, 1.5 and 2.0) nanocomposites to shed light on the combined effects of molar ratio and ball milling energy on the phase transformations and mechanical dehydrogenation. ${ }^{\mathbf{1 2 , 1 1 3}}$ For all molar ratios, $n$, the hydride nanocomposites are fully reversible at $448 \mathrm{~K}$ under a relatively mild pressure of $50 \mathrm{bar}_{2}$. To further decrease the de-/re-hydrogenation temperature of the $\mathrm{Li}-\mathrm{Mg}-\mathrm{N}-$ $\mathrm{H}$ system, Xia et al. ${ }^{\mathbf{1 1 4}}$ reported a novel multi-reaction methodology for the synthesis of nanosized $\mathrm{Li}_{2} \mathrm{Mg}(\mathrm{NH})_{2}$ space confined in thin-film hollow carbon spheres (THCSs) with a uniform dispersion, resulting in a stable cycling capacity and reversible hydrogen sorption at a temperature of $378 \mathrm{~K}$. Besides, Zhang et al. ${ }^{115}$ reported a brief review of the state-of-the art advances in improving the performances of the lightweight complex hydride $\mathrm{Li}-\mathrm{Mg}-\mathrm{N}-\mathrm{H}$ system. Due to nano effects, the space-confinement and nanoconfinement seem to be more effective for improving the hydrogen storage performance, and it is significant to develop hydrogen storage materials by studying the nanoconfined effects on the $\mathrm{Li}-\mathrm{Mg}-\mathrm{N}-\mathrm{H}$ systems.

Besides the $\mathrm{Li}-\mathrm{Mg}-\mathrm{N}-\mathrm{H}$ system, Vajo et al. ${ }^{\mathbf{1 0 3}}$ studied the $\mathrm{LiBH}_{4} / \mathrm{Mg}_{2} \mathrm{NiH}_{4}$ system due to its unique features, including full reversibility, reaction through a direct low temperature kinetic pathway, formation of a unique ternary boride phase $\left(\mathrm{MgNi}_{2.5} \mathrm{~B}_{2}\right)$, and low reaction enthalpy coupled with low entropy. The reaction begins at temperatures as low as $523 \mathrm{~K}$, which is possibly due to the catalytic nature of $\mathrm{Ni}$ in the $\mathrm{NiH}_{4}{ }^{2-}$ anion and is superior than $\mathrm{MgH}_{2}-\mathrm{LiBH}_{4} \cdot{ }^{101}$ Thus far, this system appears to be the only reversible destabilized system that reacts through a direct reaction pathway. However, its capacity (2.6 wt\%) for the direct low temperature step shown above is too low for practical use.

\subsection{Synergistic effect}

Recent research has shown that the synergistic effect, which exists in the $\gamma / \beta$ hydride phase or multi-layer $\mathrm{Mg}$ nanofilms induced by elastic constraints or interface energies, can effectively alter the desorption temperature of $\mathrm{Mg} / \mathrm{MgH}_{2}$, but this effect has not been observed directly in powders because the metal lattice is often free to expand. However, nano $\mathrm{Mg}$-based composite materials prepared by ball milling have proven that the synergistic effect produced by the high density interface between different phases can further enhance the adsorption/ dehydrogenation process, as shown in Fig. 25. The desorbing phase may be surrounded by an alternative phase and the tensile/compressive stress placed on the adjacent phase then acts as a driving force for destabilization. Significant investigations have been undertaken to improve the hydrogen storage properties of $\mathrm{Mg}$ toward the requirements of practical applications, including $\mathrm{Mg}-\mathrm{Mg}_{2} \mathrm{Ni}^{116} \mathrm{Mg}-\mathrm{Ni}-\mathrm{RE},{ }^{117} \mathrm{Mg}-\mathrm{TiCrV},{ }^{118-120}$ $\mathrm{Mg}-\mathrm{LaNi}_{x},{ }^{121,122}$ and $\mathrm{Mg}-\mathrm{TiB}_{2} /$ graphene nanosheets (GNSs). ${ }^{123}$

Zaluska et al. ${ }^{\mathbf{1 1 6}}$ reported the synergistic effects of desorption for mixtures of $\mathrm{Mg}_{2} \mathrm{NiH}_{4} / \mathrm{MgH}_{2}$ phases prepared by ball-milling. The DSC results of the mixtures showed that they could operate 


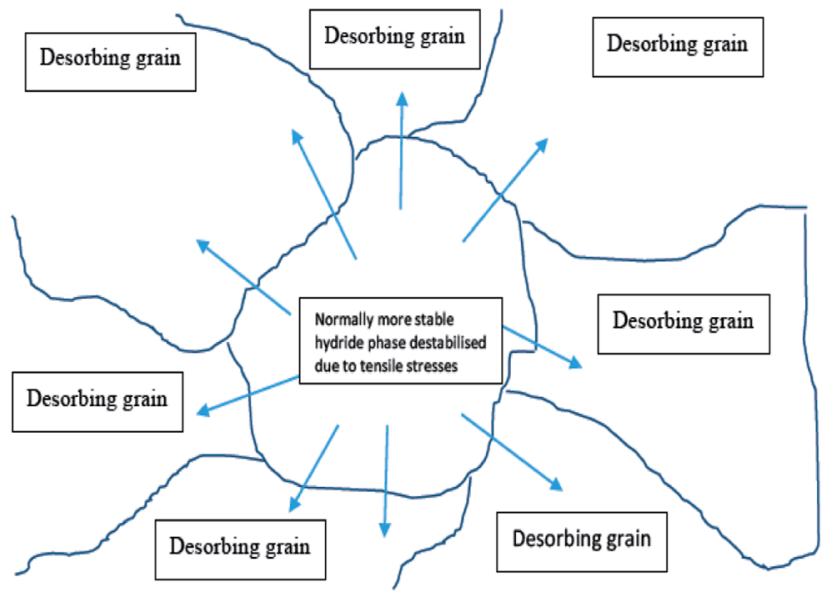

Fig. 25 Schematic representation of the potential synergistic effects observed in multiphase powders. ${ }^{70}$

at temperatures of 493-513 K. Li et al. ${ }^{\mathbf{1 1 7}}$ prepared an Mg-20 wt\% $\mathrm{Ni}-\mathrm{Y}$ composite by reactive mechanical alloying (RMA), and the $\mathrm{MgH}_{2}$ and $\mathrm{Mg}_{2} \mathrm{NiH}_{4}$ phases co-existed in the milled composite. They found that the dehydrogenation temperature of the $\mathrm{Mg}$ 20 wt $\%$ Ni-Y composite was depressed by about $100 \mathrm{~K}$ compared to that of the milled pure $\mathrm{MgH}_{2}$ due to the cocontribution of the synergetic effect of hydrogen sorption of
$\mathrm{MgH}_{2}$ and $\mathrm{Mg}_{2} \mathrm{NiH}_{4}$ and many crystal defects created by the RMA. This proves that mechanically-treated hydrides offer a new opportunity for Mg-based materials, exploiting the high capacity of magnesium hydride while operating at a much lower temperature than conventional $\mathrm{MgH}_{2}$.

Different from the synergistic effect resulting from elastic instability, Lim et al., ${ }^{\mathbf{1 2 4}}$ for the first time, prepared $\mathrm{Mg}$ nanocrystals embedded in a metal-organic framework (MOF). The Mg@SNU-9'b sample was loaded with $6.52 \mathrm{wt} \% \mathrm{Mg}$ NPs with a diagonal hexagon length ranging from 44-88 nm (Fig. 26(b)). They demonstrated that Mg-NCs@MOF is a hybrid-hydrogenstorage material that has both physical adsorption and chemisorption properties, and exhibits synergistic effects to increase the isosteric heat of $\mathrm{H}_{2}$ physisorption and to decrease the temperatures for the chemisorption/desorption of $\mathrm{H}_{2}$. Although the hydrogen storage capacities of Mg NCs@MOF were rather low at high temperature $(0.2 \mathrm{wt} \%$ and $0.24 \mathrm{wt} \%$ at $325 \mathrm{~K}$ and 415 $\mathrm{K}$, respectively) as shown in Fig. 26(d and e), the study of hybridhydrogen-storage material provides another new strategy for $\mathrm{H}_{2}$ storage and transport for the future.

Substantial Mg-based composite materials have been found by combining theoretical predictions and experimental approaches. Furthermore, the mechanism of altering the hydrogen storage properties of $\mathrm{Mg} / \mathrm{MgH}_{2}$ can be attributed to the advantages of combining many strategies including
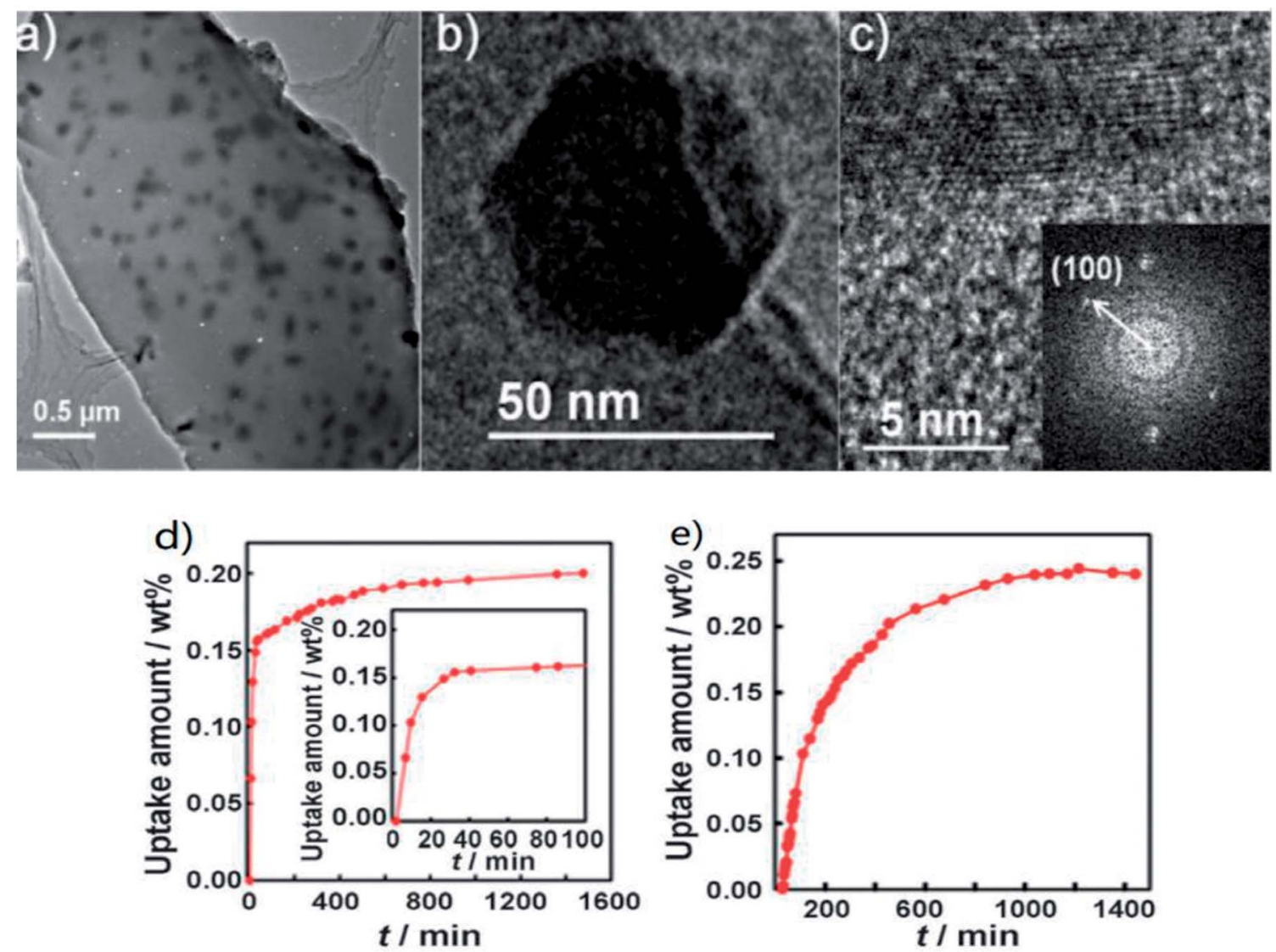

Fig. 26 High-resolution transmission electron microscopy (HRTEM) images of (a) Mg@SNU-9'b, (b) hexagonal-shaped Mg nanocrystal and (c) its edge image showing the lattice fringe (100) $d$-spacing of $\mathrm{Mg}^{0}$ (2.7782 A, JCPDS 04-0770). Inset: selected-area electron diffraction (SAED) pattern. $\mathrm{H}_{2}$ absorption kinetics of $\mathrm{Mg} @ \mathrm{SNNU}-9^{\prime} \mathrm{c}$ at (d) $325 \mathrm{~K}$ and 80 bar and (e) $415 \mathrm{~K}$ and 40 bar. ${ }^{124}$ 
alloying, surface properties, nanostructuring, synergistic effect and others, which holds potential as an on-board storage material for light-duty vehicles with a high hydrogen capacity and low desorption temperature.

\section{Conclusion and outlook}

Hydrogen energy is the one ideal means of energy storage for transportation and conversion of energy, which holds the advantages of high gravimetric energy density and carbon-free energy carrier. ${ }^{125}$ There is a generally accepted opinion that hydrogen storage materials and technologies are the key issues for the realization of a hydrogen energy economy. Among the hydrogen storage materials, magnesium-based alloys show great application prospect due to their high hydrogen storage capacity, low cost, high abundance and non-toxicity. However, they are severely limited by their high decomposition temperatures and/or poor reversibility due to unfavorable de-/ hydriding thermodynamics and/or kinetics. Despite the significant progress achieved with respect to the kinetics of hydrogen absorption/desorption in magnesium, its stable thermodynamic property is still the main drawback, which hinders its practical applications. ${ }^{126,127}$ In this review, we summarized the effective measures to alter the hydrogen storage properties of $\mathrm{MgH}_{2}$, such as alloying, nanostructuring, metastable phase formation, changing reaction paths and synergistic effects. However, all of these strategies have limitations. Alloying and changing the reaction path are the traditional and effective ways to decrease the formation enthalpy; however, at the expense of hydrogen capacity and some reactions are irreversible. Nanostructuring is a good way to change the hydrogen storage properties, but the synthesis and poor stability of nanostructures remain challenging. $\gamma-\mathrm{MgH}_{2}$ with a low formation enthalpy gradually disappears during the absorption/ desorption cycle process. Considering the advantages and disadvantages of these strategies, consequently, a new strategy, nano Mg-based composite materials, was proposed, which combined the advantages of alloy engineering, nanostructuring, and synergistic effect created by the RMM, resulting in instability in the thermodynamic properties of $\mathrm{Mg} / \mathrm{MgH}_{2}$. However, there still a long way before the $\mathrm{Mg} / \mathrm{MgH}_{2}$ system meets the criteria stipulated by the DOE for light-duty vehicles.

Based on the substantial progress, further research on $\mathrm{Mg}$ based material should focus on the following aspects:

(1) Novel preparation techniques require more attention. The synthetic approach is the first and most important step for the effective modification of the properties of Mg. Nowadays, mechanical milling, physical/chemical deposition, wet chemical routes, equal channel angular pressing and electrochemical approaches have been revisited for the synthesis of nanosized Mg. However, these approaches have failed in the advanced control over $\mathrm{Mg}$ atomic organization, crystalline-to-amorphous transitions, formation of metastable $\gamma-\mathrm{MgH}_{2}$ phase and stabilization of specific nanostructures. Thus, new synthetic routes need to be developed to control the assembly of $\mathrm{Mg}$ atoms, content of different phases, and the location and level of doping of additives/catalysts.
(2) Finding a better way to stabilize nanostructuring. Promisingly, nanostructuring can effectively alleviate kinetic barriers and reduce thermodynamic stability. However, many challenges still exist in terms of serious aggregation and structure collapse during dehydriding/hydriding. The use of scaffolds hinders particle growth and agglomeration; however, it results in a significant capacity decrease. Therefore, new forms of stabilization should be explored to maximize the storage capacity, while providing effective stabilization for nanosized $\mathrm{Mg}$ without scaffolds, such as the introduction of modified graphene nanoribbons, introduction of a second phase, storing additional hydrogen and core-shell methods, should be pursued.

(3) Predicting novel Mg-based composite materials by combining theoretical methods and experimental approaches, which can efficiently combine the advantages of alloy engineering, nanostructuring, and synergistic effects. More attention should be paid to systematic theoretical research including crystallographic/structural quantities, enthalpy/entropy/surface energy, defect formation energies and computational spectroscopy, which can be used as guidelines for the preparation of new Mg-based hydrogen materials.

Ideal storage materials with low reaction temperatures,

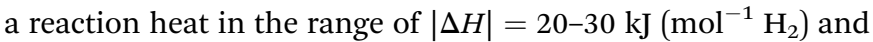
an on-board reversible hydrogen storage density of more than $6 \mathrm{wt} \% \mathrm{H}_{2}$ have not been found. However, it is expected that significant breakthrough will realize the DOE's targets with more accurate fundamental guidance and more advanced technical approaches connecting targeted properties with material microstructures.

\section{Conflicts of interest}

There are no conflicts to declare.

\section{Acknowledgements}

The authors would like to acknowledge the financial support from the Beijing Science and Technology Program (Z171100000917012) under the Beijing Municipal Science and Technology Commission.

\section{References}

1 B. Sakintuna, F. Lamari-Darkrim and M. Hirscher, Int. J. Hydrogen Energy, 2007, 32, 1121-1140.

2 C. Zhou, Z. Fang, C. Ren, J. Li and J. Lu, J. Phys. Chem. C, 2015, 117, 12973-12980.

3 H. Zijlstra and F. F. Westendorp, Solid State Commun., 1969, 7, 857-859.

4 J. J. Reilly and R. H. Wiswall, Inorg. Chem., 1968, 7, 22542256.

5 A. Züttel, Mater. Today, 2003, 6(9), 24-33.

6 ENERGY.GOV online, https://energy.gov/eere/fuelcells, accessed on June 10, 2017.

7 A. San-Martin and F. D. Manchester, Bull. Alloy Phase Diagrams, 1987, 8, 431-437. 
8 V. Bérubé, G. Radtke, M. Dresselhaus and G. Chen, Int. J. Energy Res., 2007, 31, 637-663.

9 L. Schlapbach and A. Zuttel, Nature, 2001, 414, 353-358.

10 J. P. Bastide, B. Bonnetot, J. M. Létoffé and P. Claudy, Mater. Res. Bull., 1980, 15, 1779-1787.

11 P. Vajeeston, P. Ravindran, B. C. Hauback, H. Fjellvåg, A. Kjekshus, S. Furuseth and M. Hanfland, Phys. Rev. B, 2006, 73, 224102.

12 S. Zhou, Q. Zhang, H. Chen, X. Zang, X. Zhou, R. Wang, X. Jiang, B. Yang and R. Jiang, Int. J. Hydrogen Energy, 2015, 40, 11484-11490.

13 J. F. Stampfer Jr, C. E. Holley Jr and J. F. Suttle, J. Am. Chem. Soc., 2002, 82, 3504-3508.

14 J. C. Crivello, B. Dam, R. V. Denys, M. Dornheim, D. M. Grant, J. Huot, T. R. Jensen, P. de Jongh, M. Latroche, C. Milanese, D. Milčius, G. S. Walker, C. J. Webb, C. Zlotea and V. A. Yartys, Appl. Phys. A, 2016, 122(2), 1-20.

15 C. Suryanarayana, Prog. Mater. Sci., 2004, 46, 1-184.

16 A. Baldi and B. Dam, J. Mater. Chem., 2011, 21, 4021-4026.

17 C. E. Buckley, H. K. Birnbaum, J. S. Lin, S. Spooner, D. Bellmann, P. Staron, T. J. Udovic and E. Hollar, J. Appl. Crystallogr., 2001, 34, 119-129.

18 H. Shao, G. Xin, J. Zheng, X. Li and E. Akiba, Nano Energy, 2012, 1, 590-601.

19 Y. Zhang, S. Liu, T. Yang, G. Zhang, X. Li and D. Zhao, Rare Met., 2014, 34, 1-9.

20 V. M. Skripnyuk, E. Rabkin, Y. Estrin and R. Lapovok, Acta Mater., 2004, 52, 405-414.

21 G. Cao, Nanostructures and Nanomaterials, World Scientific, New Jersey, 2004.

22 I. Haas and A. Gedanken, Chem. Commun., 2008, 15, 17951797.

23 I. P. Jain, C. Lal and A. Jain, Int. J. Hydrogen Energy, 2010, 35(10), 5133-5144.

24 J. Huot, E. Akiba and T. Takada, J. Alloys Compd., 1995, 231, 815-819.

25 J. Huot, G. Liang, S. Boily, A. V. Neste and R. Schulz, J. Alloys Compd., 1999, 293-295(51), 495-500.

26 C. Suryanarayana, E. Ivanov and V. V. Boldyrev, Mater. Sci. Eng., A, 2001, 304, 151-158.

27 R. A. Varin, T. Czujko and Z. S. Wronski, Nanomaterials for Solid State Hydrogen Storage, Springer US, New York, 2009.

28 M. Dornheim, Tailoring Reaction Enthalpies of Hydrides[M], Wiley-VCH Verlag GmbH \& Co. KGaA, 2010.

29 J. J. Reilly and R. H. Wiswall, Inorg. Chem., 1968, 7, 22542256.

30 M. Pozzo and D. Alfè, Phys. Rev. B, 2008, 77, 104103.

31 X. Hou, H. Kou, T. Zhang, R. Hu, J. Li and X. Xue, Mater. Sci. Forum, 2013, 744, 44-52.

32 N. Terashita, K. Kobayashi, T. Sasai and E. Akiba, J. Alloys Compd., 2001, 327, 275-280.

33 J. J. Reilly and R. H. Wiswall, Inorg. Chem., 1968, 7, 22542256.

34 H. Shao, G. Xin, X. Li and E. Akiba, J. Nanomater., 2013, 6, 2527-2531.
35 M. Klell, Storage of Hydrogen in the Pure Form M, Wiley-VCH Verlag GmbH \& Co. KGaA, 2010.

36 K. Batalović, J. Radaković, J. Belošević-čavor and V. Koteski, Phys. Chem. Chem. Phys., 2014, 16, 12356-12361.

37 Y. Wang, T. Aizawa and C. Nishimura, Mater. Trans., 2006, 47, 1052-1057.

38 M. Polanski, T. K. Nielsen, Y. Cerenius, J. Bystrzycki and T. R. Jensen, Int. J. Hydrogen Energy, 2010, 35, 3578-3582.

39 J. Zhang, F. Cuevas, W. Zaïdi, J. P. Bonnet, L. Aymard, J. L. Bobet and M. Latroche, J. Phys. Chem. C, 2016, 115, 4971-4979.

40 D. L. Douglass, Hydrides for Energy Storage, 1978, pp. 151184.

41 G. Liang and R. Schulz, J. Mater. Sci., 2004, 39, 1557-1562. 42 V. M. Skripnyuk and E. Rabkin, Int. J. Hydrogen Energy, 2012, 37, 10724-10732.

43 B. Thaddeus, Binary Phase Alloy Diagrams, Materials Park Ohio, 1990, pp. 2705-2708.

44 H. Zhong, H. Wang, J. Liu, D. Sun and M. Zhu, Scr. Mater., 2011, 65, 285-287.

45 H. Wang, H. Zhong, L. Ouyang, J. Liu, D. Sun, Q. Zhang and M. Zhu, J. Phys. Chem. C, 2014, 118, 12087-12096.

46 F. Luo, H. Wang, L. Ouyang, M. Zeng, J. Liu and M. Zhu, Int. J. Hydrogen Energy, 2013, 38, 10912-10918.

47 Y. Lu, H. Wang, L. Ouyang, J. Liu and M. Zhu, J. Alloys Compd., 2015, 645, S103-S106.

48 P. R. Sajanlal, T. S. Sreeprasad, A. K. Samal and T. Pradeep, Nano Rev., 2011, 2, 1-62.

49 K.-F. Aguey-Zinsou and J.-R. Ares-Fernandez, Energy Environ. Sci., 2010, 3, 526-543.

50 R. W. Wagemans, J. H. van Lenthe, P. E. de Jongh, A. J. van Dillen and K. P. de Jong, J. Am. Chem. Soc., 2005, 127, 16675-16680.

51 W. Liu and K. F. Agueyzinsou, J. Mater. Chem. A, 2014, 2, 9718-9726.

52 J. Lu, Y. J. Choi, Z. Fang and H. Y. Sohn, J. Am. Chem. Soc., 2009, 131, 15843-15852.

53 K. Asano, R. J. Westerwaal, A. Anastasopol, L. P. A. Mooij, C. Boelsma, P. Ngene, H. Schreuders, S. W. H. Eijt and B. Dam, J. Phys. Chem. C, 2015, 119, 12157-12164.

54 S. Bouaricha, J. P. Dodelet, D. Guay, J. Huot and R. Schulz, J. Mater. Res., 2001, 16, 2893-2905.

55 S. Zhou, X. Zhang, T. Li, N. Wang, H. Chen, T. Zhang, H. Yu, H. Niu and D. Liu, Int. J. Hydrogen Energy, 2014, 39, 1362813633.

56 M. Calizzi, F. Venturi, M. Ponthieu, F. Cuevas, V. Morandi, T. Perkisas, S. Bals and L. Pasquini, Phys. Chem. Chem. Phys., 2016, 18, 141-148.

57 J. A. Puszkiel, P. A. Larochette and F. C. Gennari, J. Power Sources, 2009, 186, 185-193.

58 K. J. Gross, P. Spatz, A. Zuettel and L. Schlapbach, J. Alloys Compd., 1996, 27, 206-213.

59 W. Li, C. Li, H. Ma and J. Chen, J. Am. Chem. Soc., 2007, 129, 16675-16680.

60 L. Li, B. Peng, W. Ji and J. Chen, J. Phys. Chem. C, 2009, 113, 3007-3013. 
61 H. Fujii, K. Higuchi, K. Yamamoto, H. Kajioka, S. Orimo and K. Toiyama, Mater. Trans., 2002, 43, 2721-2727.

62 K. Higuchi, K. Yamamoto, H. Kajioka, K. Toiyama, M. Honda, S. Orimo and H. Fujii, J. Alloys Compd., 2002, 330, 526-530.

63 H. Wang, L. Ouyang, C. Peng, M. Zeng, C. Chung and M. Zhu, J. Alloys Compd., 2004, 370, L4-L6.

64 S. Singh, S. W. H. Eijt, M. W. Zandbergen, W. J. Legerstee and V. L. Svetchnikov, J. Alloys Compd., 2007, 441, 344-351.

65 W. P. Kalisvaart, C. T. Harrower, J. Haagsma, B. Zahiri, E. J. Luber, C. Ophus, E. Poirier, H. Fritzsche and D. Mitlin, Int. J. Hydrogen Energy, 2010, 35, 2091-2103.

66 B. Zahiri, M. Danaie, X. Tan, S. Amirkhiz, G. A. Botton and D. Mitlin, J. Phys. Chem. C, 2011, 116, 3188-3199.

67 A. Baldi, M. Gonzalez-Silveira, V. Palmisano, B. Dam and R. Griessen, Phys. Rev. Lett., 2009, 102, 226102.

68 C. J. Chung, S. C. Lee, J. R. Groves, E. N. Brower, R. Sinclair and B. M. Clemens, Phys. Rev. Lett., 2012, 108, 106102.

69 L. P. A. Mooij, A. Baldi, C. Boelsma, K. Shen, M. Wagemaker, Y. Pivak, H. Schreuders, R. Griessen and B. Dam, Adv. Energy Mater., 2011, 1, 754-758.

$70 \mathrm{~J}$. R. H. Luke, Hydrogen sorption properties of magnesiumbased thin films, University of Birmingham, 2016.

71 S. Zhang, A. F. Gross, S. L. Van Atta, M. Lopez, P. Liu, C. C. Ahn, J. J. Vajo and C. M. Jensen, Nanotechnology, 2009, 20, 204027.

72 Y. Liu, J. Zou, X. Zeng, X. Wu, H. Tian, W. Ding, J. Wang and A. Walter, Int. J. Hydrogen Energy, 2013, 38, 5302-5308.

73 Y. S. Au, M. K. Obbink, S. Srinivasan, P. C. M. M. Magusin, K. P. De Jong and P. E. de Jongh, Adv. Funct. Mater., 2014, 24, 3604-3611.

74 Y. Jia, C. Sun, L. Cheng, W. M. Abdul, J. Cui, J. Zou, M. Zhu and X. Yao, Phys. Chem. Chem. Phys., 2013, 15, 5814-5820.

75 K. J. Jeon, H. R. Moon, A. M. Ruminski, B. Jiang, C. Kisielowski, R. Bardhan and J. J. Urban, Nat. Mater., 2011, 10, 286-290.

76 H. Li, Z. Song, X. Zhang, Y. Huang, S. Li, Y. Mao, H. Ploehn, Y. Bao and M. Yu, Science, 2013, 342, 95-98.

77 H. Jung, S. Yang, T. Kim, J. Kang and R. Chong, Carbon, 2013, 63, 165-174.

78 E. S. Cho, A. M. Ruminski, Y. Liu, P. T. Shea, S. Kang, E. W. Zaia, J. Y. Park, Y. D. Chuang, J. M. Yuk, X. Zhou, T. W. Heo, J. Guo, B. C. Wood and J. J. Urban, Adv. Funct. Mater., 2017, 27, 1704316.

79 J. Cui, H. Wang, D. Sun, Q. Zhang and M. Zhu, Rare Met., 2016, 35, 401-407.

80 M. Paskevicius, D. A. Sheppard and C. E. Buckley, J. Am. Chem. Soc., 2010, 132, 5077-5083.

81 M. Bortz, B. Bertheville, G. Böttger and K. Yvon, J. Alloys Compd., 1999, 287(3), 4-6.

82 J. Huot, G. Liang, S. Boily, A. V. Neste and R. Schulz, J. Alloys Compd., 1999, 293-295, 495-500.

83 X. Xiao, Z. Liu, S. Saremiyarahmadi and D. H. Gregory, Phys. Chem. Chem. Phys., 2016, 18, 10492-10498.

84 C. Ren, Z. Fang, C. Zhou, J. Lu, Y. Ren, X. Zhang and X. Luo, Int. J. Hydrogen Energy, 2014, 39, 5868-5873.
85 C. Shen and K. F. Aguey-Zinsou, J. Mater. Chem. A, 2017, 5, 8644-8652.

86 M. Ponthieu, F. Cuevas, J. F. Fernández, L. Laversenne, F. Porcher and M. Latroche, J. Phys. Chem. C, 2013, 117, 18851-18862.

87 F. C. Gennari, F. J. Castro and G. Urretavizcaya, J. Alloys Compd., 2001, 321, 46-53.

88 Y. Song and Z. Guo, Appl. Phys. Lett., 2006, 89, 151.

89 J. J. Vajo, T. T. Salguero, A. F. Gross, S. L. Skeith and G. L. Olson, J. Alloys Compd., 2007, 446(1), 409-414.

90 J. J. Vajo, F. Mertens, C. C. Ahn, R. C. Bowman and B. Fultz, Cheminform, 2004, 35, 13977-13983.

91 A. L. Chaudhary, D. A. Sheppard, M. Paskevicius, C. J. Webb, E. M. Gray and C. E. Buckley, J. Phys. Chem. C, 2013, 118, 1240-1247.

92 S. T. Kelly, S. L. Van Atta, J. J. Vajo, G. L. Olson and B. M. Clemens, Nanotechnology, 2009, 20, 204017.

93 F. C. Gennari, F. J. Castro, G. Urretavizcaya and G. Meyer, J. Alloys Compd., 2002, 334, 277-284.

94 G. S. Walker, M. Abbas, D. M. Grant and C. Udeh, Chem. Commun., 2011, 47, 8001-8003.

95 S. Bouaricha, J. P. Dodelet, D. Guay, J. Huot, S. Boily and R. Schulz, J. Alloys Compd., 2000, 297, 282-293.

96 J. C. Crivello, T. Nobuki and T. Kuji, Int. J. Hydrogen Energy, 2009, 34, 1937-1943.

97 S. Kalinichenka, L. Röntzsch, T. Riedl, T. Weißgärber and B. Kieback, Int. J. Hydrogen Energy, 2011, 36, 10808-10815.

98 H. Lin, W. Wang and M. Zhu, J. Non-Cryst. Solids, 2012, 358, 1387-1390.

99 A. Ming, Mater. Sci. Eng., B, 2005, 117, 37-44.

100 N. Zhou and D. Ju, Int. J. Hydrogen Energy, 2014, 39, 1963019636.

101 S. Kumar, U. Jain, A. Jain, H. Miyaoka, T. Ichikawa, Y. Kojima and G. K. Dey, Int. J. Hydrogen Energy, 2017, 47, 3963-3970.

102 S. V. Alapati, J. J. Karl and D. S. Sholl, Phys. Chem. Chem. Phys., 2007, 38, 1438-1452.

103 J. J. Vajo, W. Li and P. Liu, Chem. Commun., 2010, 46, 66876689.

104 H. Liu, X. Wang, Y. Liu, Z. Dong, H. Ge, S. Li and M. Yan, J. Phys. Chem. C, 2014, 118, 37-45.

105 M. Jurczyk, M. Nowak, L. Smardz and A. Szajek, $M g-B A S E D$ NANOCOMPOSITES FOR ROOM TEMPERATURE HYDROGEN STORAGE, Tms 1 Meeting \& Exhibition, 2011.

106 L. E. Klebanoff and J. O. Keller, Int. J. Hydrogen Energy, 2013, 38, 4533-4576.

107 Y. Liu, K. Zhong, M. Gao, J. Wang, H. Pan and Q. Wang, Chem. Mater., 2008, 20, 3521-3527.

108 J. J. Hu, E. Rohm and M. Fichtner, Acta Mater., 2011, 59, 5821-5831.

109 J. Lu, Y. J. Choi, Z. Z. Fang and Y. Hong, J. Power Sources, 2010, 195, 1992-1997.

110 J. Lu, Z. Z. Fang, Y. J. Choi and H. Y. Sohn, MRS Online Proc. Libr., 2007, 111, 12129-12134.

111 O. Dolotko, N. Paulson and V. K. Pecharsky, Int. J. Hydrogen Energy, 2010, 35, 4562-4568. 
112 R. Parviz and R. A. Varin, Int. J. Hydrogen Energy, 2013, 38, 8313-8327.

113 R. A. Varin, R. Parviz, M. Polanski and Z. S. Wronski, Int. J. Hydrogen Energy, 2014, 39, 10585-10599.

114 G. Xia, X. Chen, C. Zhou, C. Zhang, D. Li, Q. Gu, Z. Guo, H. Liu, Z. Liu and X. Yu, J. Mater. Chem. A, 2015, 3, 12646-12652.

115 B. Zhang and Y. Wu, Prog. Nat. Sci.: Mater. Int., 2017, 27(1), 21-33.

116 A. Zaluska, L. Zaluski and J. O. Ström-Olsen, J. Alloys Compd., 1999, 289, 197-206.

117 Z. Li, X. Liu, L. Jiang and S. Wang, Int. J. Hydrogen Energy, 2007, 32, 1869-1874.

118 L. Laversenne, J. Andrieux, D. Plante, L. Lyard and S. Miraglia, Int. J. Hydrogen Energy, 2013, 38, 11937-11945. 119 X. Liu, Z. Huang, L. Jiang and S. Wang, Int. J. Hydrogen Energy, 2007, 32, 965-968.
120 C. Zhou, Z. Z. Fang, C. Ren, J. Li and J. Lu, J. Phys. Chem. C, 2013, 117, 12973-12980.

121 F. Li, L. Jiang, J. Du, S. Wang, X. Liu and F. Zhan, Int. J. Hydrogen Energy, 2006, 31, 581-585.

122 G. Liang, S. Boily, J. Huot, A. V. Neste and R. Schulz, J. Alloys Compd., 1998, 268, 302-307.

123 G. Liu, Y. Wang, L. Jiao and H. Yuan, Int. J. Hydrogen Energy, 2014, 39, 3822-3829.

124 D. W. Lim, J. W. Yoon, K. Y. Ryu and M. P. Suh, Angew. Chem., 2012, 51, 9814-9817.

125 B. P. D. Ulf, E. P. D. Baldur and G. Taylor, Cogeneration and Competitive Power Journal, 2003, 18(3), 29-70.

126 X. B. Yu, Z. W. Tang, D. L. Sun, L. Z. Ouyang and M. Zhu, Prog. Mater. Sci., 2017, 88, 1-48.

127 I. Z. Hlova, Mechanochemical synthesis of hydrogen-storage materials based on aluminum, magnesium and their compounds, Iowa State University, 2015. 